\title{
Interaction of Electrical Energy Storage, Flexible Bioenergy Plants and System-friendly Renewables in Wind- or Solar PV-dominated Regions
}

\author{
Philip Tafarte ${ }^{1,2}, *(\mathbb{D})$, Annedore Kanngießer ${ }^{3}$, Martin Dotzauer ${ }^{4}$, Benedikt Meyer ${ }^{5}{ }^{(}$, \\ Anna Grevé ${ }^{3}$ and Markus Millinger ${ }^{1}$ (D) \\ 1 Department Bioenergy-UFZ, Helmholtz Centre for Environmental Research, Permoserstr. 15, 04318 Leipzig, \\ Germany; markus.millinger@ufz.de \\ 2 Department of Economics-UFZ, Helmholtz Centre for Environmental Research, Permoserstr. 15, \\ 04318 Leipzig, Germany \\ 3 Fraunhofer Institute for Environmental, Safety and Energy Technology UMSICHT, Osterfelder Str. 3, \\ 46047 Oberhausen, Germany; annedore.kanngiesser@umsicht.fraunhofer.de (A.K.); \\ anna.greve@umsicht.fraunhofer.de (A.G.) \\ 4 Division Bioenergy Systems, DBFZ Deutsches Biomasseforschungszentrum Gemeinnützige GmbH, \\ Torgauer Straße 116, 04347 Leipzig, Germany; Martin.Dotzauer@dbfz.de \\ 5 Advanced Energy Systems Institute, Universität Bremen, Enrique-Schmidt-Str. 7, 28359 Bremen, Germany; \\ benedikt.meyer@uni-bremen.de \\ * Correspondence: philip.tafarte@ufz.de
}

Received: 31 December 2019; Accepted: 20 February 2020; Published: 3 March 2020

\begin{abstract}
Wind and solar PV have become the lowest-cost alternatives for power generation in many countries and are expected to dominate the renewable power supply in many regions of the world. The temporal volatility in power production from these sources leads to new challenges for a stable and secure power supply system. Possible technologies to improve the integration of wind and solar $\mathrm{PV}$ are electrical energy storage and the flexible power provision by bioenergy. A third option is the system-friendly layout of wind and solar PV systems and the optimized mix of wind and solar PV capacities. To assess these different options at hand, a case study was conducted covering various scenarios for a regional power supply based on a high share of wind and solar PV. State-of-the-art concepts for all the stated technologies are modelled and a numerical optimization approach is applied on temporally-resolved time series data to identify the potential role of each option and their respective interactions. Power storage was found to be most relevant in solar dominated systems, due to the diurnal generation pattern, whereas bioenergy is more suitably combined with high wind power shares due to the less regular generation pattern. System-friendly wind and solar power can reduce the need for generation capacity and flexible options by fitting generation and demand patterns better.
\end{abstract}

Keywords: integration of variable renewables; electric energy storage; flexible bioenergy; energy system modelling

\section{Introduction}

In order to reduce the climate impact of power generation, Germany, along with many other countries, strives for an energy system dominated by renewable generation options [1]. In Germany, the promising scalable options at hand - wind and solar power-are variable renewable energy sources (vRES), which lead to new challenges to match power demand and supply. The supply from vRES depends on the local availability of the solar irradiation and the kinetic energy of air at the locality 
of the energy converters, which is inherently variable and only to a certain degree deterministic. For power systems which require an instantaneous balance of demand and supply in order to maintain their stability, this has a very large impact on the infrastructure and operation in comparison to conventional power supply systems with a dispatchable supply of power [2]. Numerous solutions have been proposed to address this challenge. Connecting power grids with higher capacity transmission grids $[3,4]$ increases the spatial spread of wind and solar power generation, and thereby geographic temporal generation and demand fluctuations may be alleviated to some extent, while also increasing the utilization of untapped solar and wind resources. Power demand can also, to some extent, be adapted to the fluctuating supply from vRES through so called demand side management (DSM) [5]. System-friendly adaptations of the technical layout of wind and solar power plants, which entail wind turbines with lower specific power ratings in relation to their rotor swept area and solar PV systems in an east and west-facing azimuth orientation, reduce the variability in power supply from vRES [6,7] as well as providing a better coverage of the temporal consumption patterns.

Several direct balancing options also exist. Electric energy storage systems (EESS) can be used to store energy at times of surplus power supply, in order to use it at times of supply deficits [8-11]. Through connecting different grids, the hydro power capacities of certain regions, such as Scandinavia, can be used for balancing other regions [12]. Bioenergy is another renewable option, with the benefit of long storability combined with the technical flexibility to offset some of the variability in power production from wind and solar [13,14]. In some regions with high direct solar radiation concentrated solar power (CSP) may also serve as a flexible option, but in Germany this is not a viable option [15].

Many studies assume large, pan-European grids, which postpone the need for other balancing options. Under such conditions, EESS have been estimated to be required at renewables shares of above $70 \%$ or higher [16-18]. In a regional context, balancing options would be required already at lower renewables shares, while the relevance of system-friendly solutions increases. An assessment of the potential relevance of these options (EESS, system-friendly renewables, and flexible bioenergy) in combination with a sub-national regional level provides an important contrast to previous studies, and maps out a solution space for decision makers.

In this paper, two German regions dominated by wind and solar power, respectively, are used as a basis for investigating the potential role of system-friendly wind and solar power, EESS and bioenergy at different vRES shares. The following research questions are assessed in this paper:

1. How can EESS and flexible bioenergy contribute to reduce challenges connected to the integration of large shares of vRES in wind or solar power-dominated regions?

2. How can system-friendly wind and solar power contribute to reduce challenges connected to the integration of large shares of vRES in wind or solar power-dominated regions?

3. What is the interaction of these balancing options?

\section{Methodology}

To answer the three given research questions, a four-step approach is applied as displayed in Figure 1: 


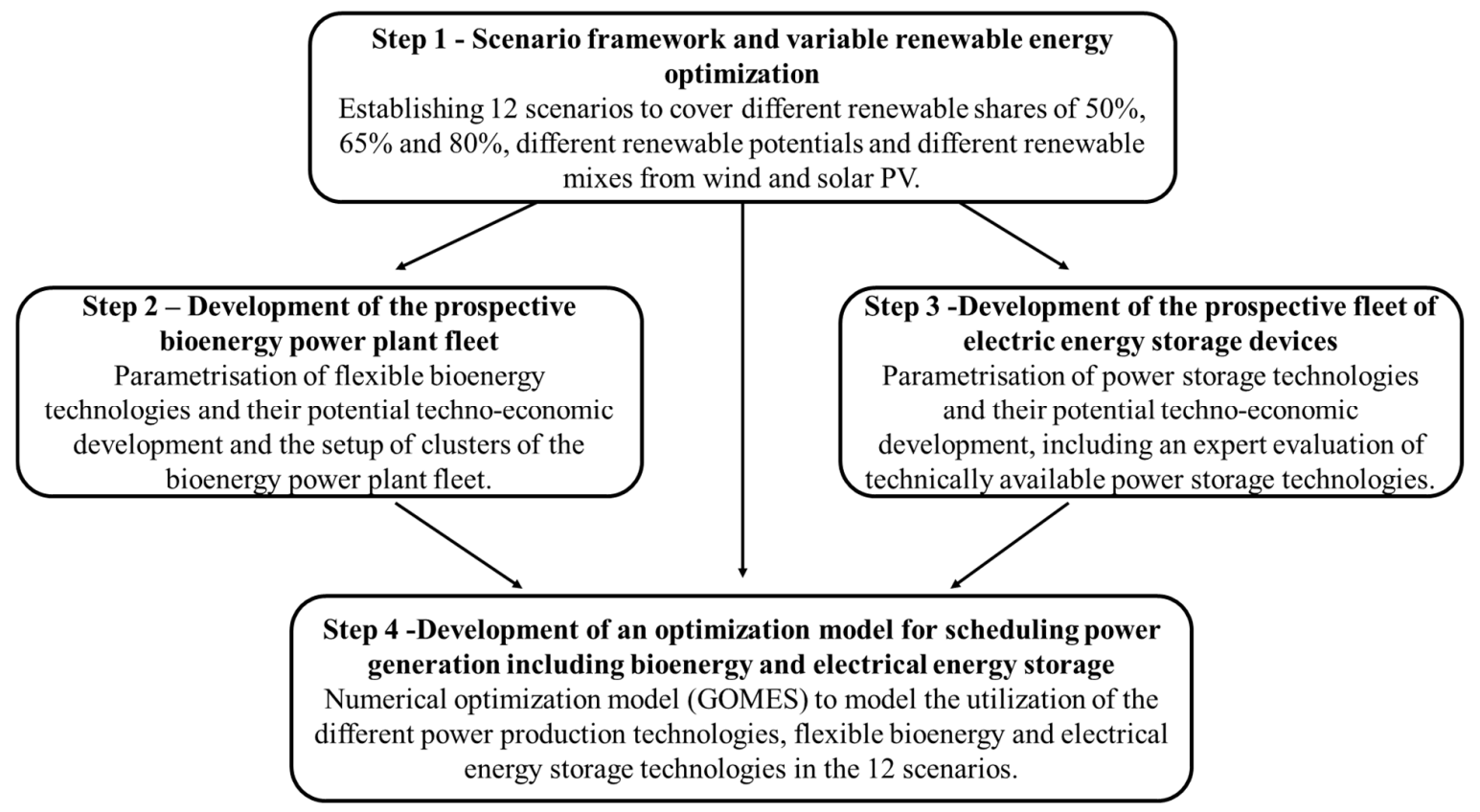

Figure 1. Methodological overview.

\subsection{Step 1: Scenario Framework and Variable Renewable Energy Optimization}

Scenarios differ regarding the respective share of renewables of $50 \%, 65 \%$, and $80 \%$, on electricity consumption which are (sub-ordinate) targets in Germany for the next decades. Furthermore, the scenarios cover the mayor vRES sources wind and solar PV with their specific temporal production patterns as well as different renewables mixes from wind and solar PV, which are either exogenously predefined (CLASSIC scenarios) or endogenously optimized (VAREO scenarios). Therefore, both groups comprise six individual scenarios (cf. Table 1), leading to 12 considered scenarios in total.

Table 1. Overview of all 12 scenarios.

\begin{tabular}{cccc}
\hline & $\begin{array}{c}\text { Target Share of } \\
\text { Renewables }\end{array}$ & $\begin{array}{c}\text { vRES Mix } \\
\text { Exogenously } \\
\text { Defined }\end{array}$ & $\begin{array}{c}\text { vRES Mix } \\
\text { Endogenously } \\
\text { Optimized }\end{array}$ \\
\cline { 2 - 4 } Solar PV-dominated region & $50 \%$ & CLASSIC & VAREO \\
\cline { 2 - 4 } & $65 \%$ & CLASSIC & VAREO \\
\hline \multirow{3}{*}{ Wind-dominated region } & $80 \%$ & CLASSIC & VAREO \\
\cline { 2 - 4 } & $50 \%$ & CLASSIC & VAREO \\
\cline { 2 - 4 } & $65 \%$ & CLASSIC & VAREO \\
\hline
\end{tabular}

\subsubsection{Scenario Development}

The CLASSIC scenarios are derived from the capacity expansion pathways for wind and solar PV as projected in the German network development plan [19] for 2032. Hence, the capacity mix for wind and solar PV is exogenously determined by the network development plan. As the capacity mix is exogenously set in the CLASSIC scenarios, the installed wind and solar capacities are both proportionally scaled to target the shares of renewable of $50 \%, 65 \%$ and $80 \%$ respectively (cf. Section 2.2), that are projected for the long term development of Germany's power system [20]. This scaling of wind and solar PV capacities also approximates the contribution of electrical energy storage to calculate its contribution to achieve the set renewables shares (cf. Section 3.1.2). 
The VAREO scenarios, in contrast, entail two additional optional modifications in order to improve the integration of vRES in the first place. One additional option is a capacity mix from wind and solar PV that is endogenously optimized by the VAREO model. The other additional option included in the VAREO scenarios are system-friendly layouts for wind and solar PV [7,21]. Both options have the potential to improve the supply by vRES in comparison to the exogenously determined mix from wind and solar PV and the standard vRES layouts to which the CLASSIC scenarios are restricted. The system-friendly layouts entail wind turbines with higher full load hours (FLH) designed for low to medium wind resources as well as solar PV installations facing towards east and west for a better temporal coverage of daily consumption patterns by the resulting vRES feed-in. For the modelling of feed-in time series for system-friendly layouts in the VAREO scenarios, it is also referred $[6,21]$. The general idea of the optimized capacity mix and the system-friendly layouts is to minimize the surplus power production from vRES over the course of the residual load time series, also described as excess energy. Wind and solar PV capacities, including those system-friendly layouts, are therefore composed to minimize excess energy and not exogenously determined as it is the case for the CLASSIC scenarios.

The know advantages of system-friendly layouts regarding the feed-in of vRES are of increasing relevance especially for power systems with low flexibility and already high vRES shares where their potential to improve the integration of vRES power sources is higher as outlined by [22]. However, for power systems with lower shares of renewables or significant flexibility options, like pump hydro storage capacities, slightly higher LCOE from system-friendly might offset the specific advantages of system-friendly renewables [22-24].

Furthermore, within both groups the scenarios are split into a wind-dominated region as well as a solar PV-dominated region. Correspondent to the projections of the network development plan the transmission system of 50 Hertz Transmission GmbH in the northeast of Germany $\left(109,619 \mathrm{~km}^{2}\right.$, 18.2 million inhabitants) serves as the wind-dominated case study region (onshore wind as well as offshore wind). The transmission system of TRANSNET-BW in the southwest of Germany $\left(34,600 \mathrm{~km}^{2}\right.$, 10 million inhabitants) serves as the solar PV dominated case study region.

The energetic volume (TWh) and the development of the prospective bioenergy power plant fleet (cf. Section 2.2) varies together with the prospective fleet of EESS (cf. Section 2.3) between the solar PV-dominated region and the wind-dominated region, but is kept constant between CLASSIC and VAREO scenario groups.

Likewise included in the calculation of the share of renewables for all scenarios is the contribution of hydro power, geothermal power, and other renewables (mainly the biogenic fraction of household waste used in incineration plants).

\subsubsection{Time Series Data for Wind Feed-in, Solar PV Feed-in and Power Consumption}

All 12 scenarios are based on time series data for the duration of one year, starting on the 30th of June 2011 up to the 1st of July 2012. The time series data for the renewables feed-in provided by the two transmission system operators (TSO) are normalized and scaled [6], so that the productivity of the installed capacity in terms of FLH is equivalent to the FLH given in [19] for the year 2032 of the CLASSIC scenario group. Time series data for offshore wind in the wind-dominated region is derived from wind speed time series data of the FINO 2 platform in the Baltic Sea. Consumption time series are likewise scaled to match an annual power consumption of $57.8 \mathrm{TWh} / \mathrm{a}$ in the solar PV-dominated region for 2030 and $87.6 \mathrm{TWh} / \mathrm{a}$ in the wind-dominated region for 2030 and further developing until 2050 according to scenario $\mathrm{A}$ in [20].

The resulting generation capacities (cf. Tables A1 and A2) and the residual load duration curves for all 12 scenarios (cf. Figure 6 and Figure A1) are provided in the results section and the Appendix A. 


\subsection{Step 2: Development of the Prospective Bioenergy Power Plant Fleet}

In a second step, for three different shares of renewables of 50\%, 65\%, and $80 \%$ relevant bioenergy technologies, were described regarding their potential capacity and techno-economic development. This description serves as input parameters for the modelling of these bioenergy technologies. A clustering approach according to [19] aggregates the different technologies into three groups.

Each group was represented by a typical technology or rather a sample plant with characteristic qualities towards demand driven energy provision. In detail there were biomethane-fired combined heat and power units (CHPU) (this group also includes vegetable oil-powered cogeneration plants), biogas plants with local combined heat and power generation (this group also includes wood gas CHPU), and thermodynamic cycle biomass power plants, labeled as wood-fired power plants. In general, we assume that bioenergy technologies for power generation can be divided into two sub-processes, with the exception of biomethane-CHPU. Biomethane-CHPU represent just a single conversion process, were the fuel is converted into electrical and thermal energy. Thus, the second group, namely biogas plants and for wood-fired power plants, the raw material is first converted in a secondary energy carrier (biogas or steam). In a second conversion step this energy carrier is converted into (secondary) heat and power. This subdivision is required to describe the different behaviors of all three technology groups.

To estimate the future plant portfolio for an energy-system with different shares of renewables the quantity of electrical work in a certain scenario is allocated to the three technology groups, according to their respective share in 2015 [25]. The absolute amount of power generation from bioenergy of each group was extrapolated based on the relative changes of power generation from 2015, with 31.5\% renewable energy share (RES), compared to increasing RES up to $50 \%, 65 \%$, and $80 \%$, referring to Section 2.1. As an additional assumption a partitioning between inflexible and flexible plants was set. At present just a part of all bioenergy plants are flexible and it is unlikely that in future the whole plant inventory will be flexibilized, because of technical limitations and change inertia of plant operators. However, it is supposed that a growing number of plants will be flexible in the future. For each of the technology groups a reference plant with an individual parameter set for today and the three future scenarios were designed. These parameters are depicted in Tables A3 and A4 for the cluster biogas plant with on-site CHPU and in Table A5 for the cluster wood-fired power plant. All tables are part of the Appendix A.

The main differences between those groups are first of all the absolute degrees of flexibility $\left(\mathrm{Q}_{\mathrm{P}}\right)$, where the biogas plant can deliver a higher amplitude of controllable load. However, it is important to underline that biogas plants with on-site CHPU are subject to the restrictions of gas storage capacity, so they cannot operate on as well as off just for a limited amount of time. Even when the CHPU is off, the biological process of fermentation is going on and consciously producing gas. Furthermore, it is assumed, that within the scenario for $80 \%$ RES the all biogas plants operated flexibly $\left(\mathrm{SHR}_{\mathrm{flx}}=100 \%\right)$, while $20 \%$ of the wood-fired power plants stay inflexible, due to technical restrictions. Thus, the quality of flexibility for the whole portfolio depends not only on the single (flexible) plant but also on the proportion of flexible plants of the certain group.

\subsection{Step 3: Development of the Prospective Fleet of EESS}

In parallel, all the relevant electrical energy storage technologies and their potential techno-economic development were likewise described in the third step. An expert evaluation of the wide range of technically available electrical energy storage technologies was carried out to assess and attribute the technologies with estimated techno-economic data until 2050 (see Tables A6 and A7 in the Appendix A). At first technologies which principally meet the requirements of the short and mid-term storage demand are clustered: short-term: lead-, lithium-, and nickel-based storage systems; mid-term: compressed air energy-, pump-hydro-, redox flow-, and high temperature storage systems. For each technology a comprehensive literature research regarding the relevant techno-economic data was performed to get input data for the following process. In parallel, the residual load profile had to be analyzed to scale the overall EESS capacity and power needed depending on 
the scenario. To derive a fleet of electrical energy storages a share of each technology based on the techno-economic data and EESS capacity and power was determined adopting the analytic hierarchy process (AHP) [26-28].

The scenarios described in Section 2.1 lead to different residual load profiles thus different fleets of EESS were needed. The aim of this study was to use an optimum of the renewable generated electricity. Hence the scale of electrical energy storage systems was designed in accordance to the maximum negative residual load of the CLASSIC scenarios for short-term and mid-term storage, respectively. Short-term storage demands address occurrences of negative residual loads within an hour, while mid-term storage demands address occurrences of negative residual loads from a few hours up to three days.

To form the fleet of EESS systems by defining the share of each technology for short and mid-term EESS, the analytic-hierarchy-process (AHP) used in the field of decision finding was adapted from that described in [20-22]. The main aspect of this process is the pairwise comparison of the categories and the criteria to each other to identify the most preferable option for specific predefined problems. Instead of evaluating different alternatives of EESS the AHP is used to determine a share of each technology within the short- and medium-term cluster. For each EESS cluster relevant criteria to describe the technologies were again clustered in three categories: environmental effects, technical parameters and economic parameters. Within these clusters relevant criteria had been identified and are shown in Table 2 exemplarily for short-term electrical energy systems along with their weighing factor or significance. The weighing factors of the different criteria are a result mainly derived by the pairwise comparison of the categories and the criteria within each category. This method shows that the most significant criteria are cycling capability, efficiency and costs.

Table 2. Global and local weighing factors for short-term electrical energy storage systems.

\begin{tabular}{|c|c|c|c|c|c|c|c|c|}
\hline Environmental Effects & $\begin{array}{l}\text { Global } \\
10.5 \%\end{array}$ & Local & $\begin{array}{l}\text { Technical } \\
\text { Parameters }\end{array}$ & $\begin{array}{l}\text { Global } \\
63.7 \%\end{array}$ & Local & Economic Parameters & $\begin{array}{c}\text { Global } \\
25.8 \%\end{array}$ & Local \\
\hline Land use & $0.4 \%$ & $3.4 \%$ & Efficiency & $20.5 \%$ & $32.2 \%$ & Power-related cost & $10.7 \%$ & $41.4 \%$ \\
\hline Environmental hazards & $0.8 \%$ & $7.7 \%$ & Self-discharge & $2.2 \%$ & $3.4 \%$ & Capacity-related cost & $5.7 \%$ & $22.0 \%$ \\
\hline Infrastructure emissions & $3.6 \%$ & $34.3 \%$ & Cyclebility & $25.8 \%$ & $40.4 \%$ & Operating cost & $2.4 \%$ & $9.2 \%$ \\
\hline Raw material criticality & $2.3 \%$ & $21.5 \%$ & Lifespan & $8.9 \%$ & $13.9 \%$ & Starting cost & $6.4 \%$ & $25.0 \%$ \\
\hline
\end{tabular}

To derive practicable data from literature research or expert guesses, some of the above-shown criteria, e.g., acceptance or plant availability, are described by a qualitative assessment (see Table A8 in the Appendix A). The used specific data for each scenario is given in the Appendix A (see Tables A6 and A7). Applying the normalized specific data of each technology and the weighing factors (see Table 2 above and Table A9 in the Appendix A) leads to a specific share of each technology within the clusters. According to the identified scale of EESS capacity and power, different fleets of energy storage systems resulted from the AHP, which are provided, in Table A10 in the Appendix A.

\subsection{Step 4: Development of an Optimization Model for Scheduling the Fleet's Operation}

The processed data from the three previously described steps were utilized in the numerical optimization model derived from GOMES ${ }^{\circledR}$ (Generic Optimization Model for Energy Storage) which is a mixed-integer, linear optimization model for the techno-economic evaluation of EESS applications [29].

The enhanced model was applied to assess the utilization of the different power generation technologies, including fossil power plants (hard coal power plant, gas-steam power plant), flexible bioenergy plants (biomethane CHPU, biogas CHPU, wood-fired CHPU) as well as short-term and mid-term EESS in the different scenarios. In addition, a "reserve" power plant (in dependence on fast-starting gas turbines) was introduced to ensure residual load covering in each time step. The minimization of greenhouse gas emissions served as the objective function for the optimization. 
Moreover, a rolling horizon was applied to limit the perfect foresight to a timeframe of two days. Only the first day's results were put on record, the second day served as an overlap that is designed to avoid the emptying of electrical energy storage at the end of each day which could lead to a local instead of the global optimum. The results of this final step are used to study the potentials and the interaction of the different technologies for each of the 12 different scenarios.

Minimization of greenhouse gas emissions was chosen as the objective function because it goes hand in hand with the maximal achievable amount of electricity production by renewable energies, which is the overall goal. The formulation of the objective function can be found in Equation (1). The amount of emissions is calculated by summing up the emissions of each fossil-fueled plant for each time step $t$ in each optimization run $T$ within the rolling horizon. In addition, a penalty factor has been introduced for the gas-fueled power plant and the reserve power plant. The factor serves to respect the economic merit-order of the plants that is formed at the spot market by their marginal costs [30] (in contrast to the ecological order of the fossil-fueled plants, where gas has lower specific greenhouse gas emissions than coal, the economic merit-order of the plants gives preference to the coal-fueled plants, because they have lower marginal costs). As a result, the objective function prefers the feed-in of renewable energy which will be stored during a surplus situation, or the feed-in of flexible bioenergy plants. The fossil-fueled power plants are only operated if no emission-free electricity can be produced and respectively discharged.

$$
\operatorname{minCO} 2=\sum_{\mathrm{T}=1}^{365} \sum_{\mathrm{t}=1}^{\mathrm{n}}\left(\mathrm{CO}_{2, \text { hardcoal }}(\mathrm{t})+5 \cdot \mathrm{CO}_{2, \text { gas }}(\mathrm{t})+100 \cdot \mathrm{CO}_{2, \text { reserve }}(\mathrm{t})\right)
$$

The most important constraint for ensuring security of supply and a stable grid operation says that positive residual load (resulting from methodical step 1) has to be covered in each time step t. In contrast, the remaining negative residual load is allowed. It is understood that the remaining negative residual load, i.e., surplus of electricity production, is used in cross-sectoral appliances. Possible examples of cross-sectoral appliances include power-to-heat (e.g., heat pumps or electric boilers) or power-to-gas appliances (production of hydrogen from electrolysis of water), but there are many other relevant options [31-34].

A further restriction ensures that flexible biomass plants are able to produce energy throughout the whole year. For this the predicted annual amount of biomass substrate (cf. Section 2.2) is broken down for each optimization run $\mathrm{T}$ in proportion to the amount of positive residual load during this optimization run T. In addition, several constraints concerning the plant operation were applied for optimization, e.g., installed power and capacity, ability for part load operation, receivable ramp rates, self-discharge rate, limited numbers of starts per day, minimum idle time, as well as minimum operating time. Further information about the restrictions can be found in the Appendix A (Table A11).

\section{Scenario Analysis}

To answer the first research question about the contribution of EESS and flexible bioenergy for the integration of large shares of vRES, the results of CLASSIC scenarios are presented (cf. Section 3.1). Afterwards, Section 3.2 presents the results of VAREO scenarios to evaluate the contribution of system-friendly wind and solar energy. Third, the interaction of the different balancing options is analyzed in Section 3.3. For this purpose, additional alternative scenario runs were carried out, in which single balancing options were excluded or changed.

\subsection{Results of CLASSIC Scenarios}

Initially, the covering of remaining residual load by the different plants or EESS is shown and monitored effects are discussed. Subsequently, the achieved share of renewables is analyzed in more detail. Afterwards, some characteristic figures regarding operation of the different plants and EESS are 
discussed. Finally, the characteristics of remaining excess energy and power is presented in the context of its potential usage for sector coupling purposes.

\subsubsection{Electricity Production}

Figure 2 shows how the remaining positive residual load of the model regions, i.e., the load after feed-in of renewable power plants and must-run power plants, is covered by the different flexible power plants or EESS. In both regions the share of $\mathrm{CO}_{2}$-emission-free electricity production increases from 2030 to 2050. In the solar region a larger amount of renewable energy is shifted over time by EESS than in the wind region. This can be for two different reasons: On the one hand, it is possible that EESS do not match so well with the characteristic pattern of the remaining positive residual load. On the other hand, the high share of bioenergy feed-in, potentially resulting from their larger installed capacity, could have obstructed energy shifting by EESS. The proportion of the feed-in of the different bioenergy plant types also reflects the proportion of their installed power. Moreover, it is remarkable that there is no electricity produced by coal plants in the solar region in 2050, in spite of the penalty factor in the objective function that prefers coal plants. This phenomenon can be explained by the slower ramping behavior of the coal power plant in contrast to the gas-steam power plant. Alternatively, this phenomenon could be caused by the lengthy minimum operating period or lengthy minimum shutdown period of the coal power plant. It is also possible that both reasons contribute to the phenomenon.

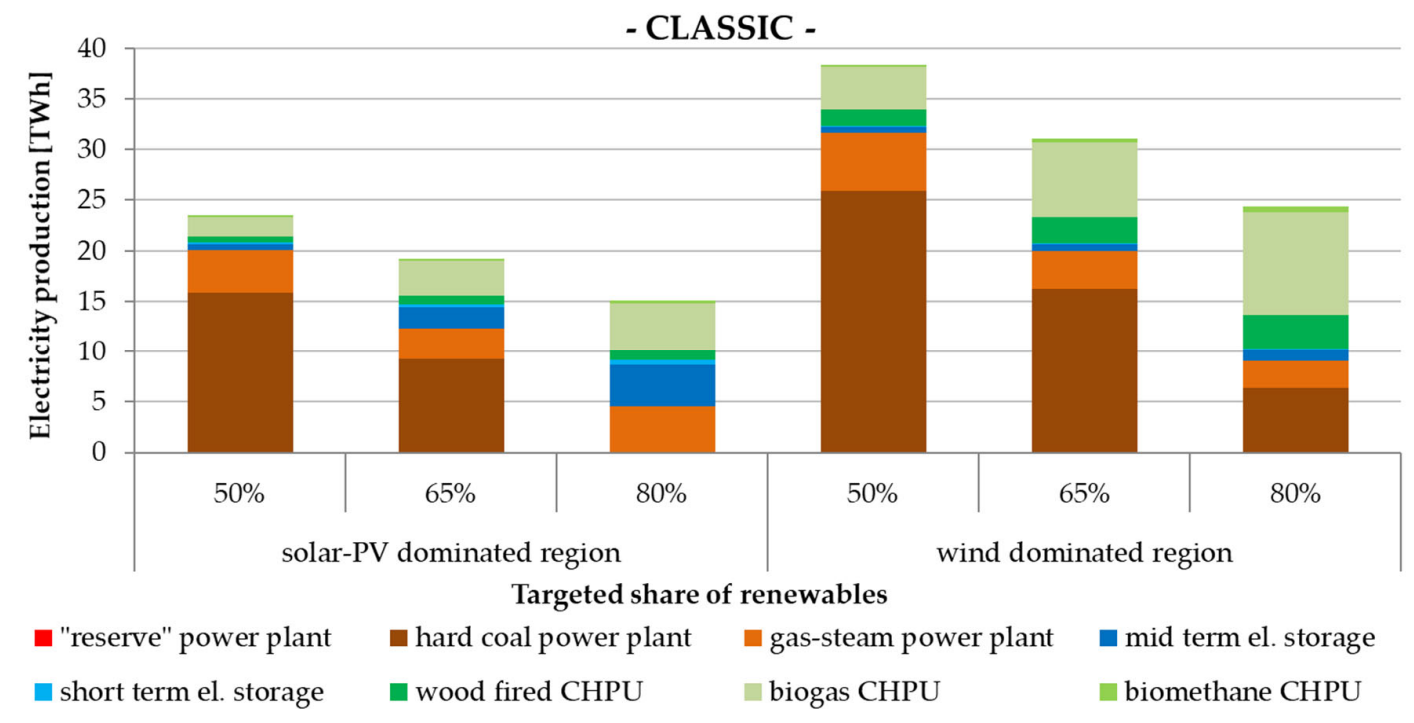

Figure 2. Covering of remaining residual load by the different plants or EESS of the fleet.

\subsubsection{Achieved share of renewables}

As a result of the production mix presented in, as well as the previous electricity production by renewables (cf. methodical step 1), Figure 3 illustrates the achieved share of renewables in the electricity consumption of both regions. The dark grey section of the bars represents the share of renewables before using flexible bioenergy plants or EESS, that means wind and solar power, run-of-river, geothermal energy and the inflexible baseload of biomass plants. The light grey section represents the renewable feed-in from flexible bioenergy power plants and EESS (per time shifting of former negative residual load). The black rhombus in each bar represents the targeted share of renewables for each particular scenario and has to be read from the left axis. It shows that the desired share of renewables is reached or exceeded in the solar region, but is slightly underachieved in the wind region. The reason for the deviation between the achieved share of renewables and the target share of renewables is the rough estimation in methodological step 1 about the amount of excess energy that can be time-shiftable by 
EESS when determining the installed capacities for wind energy and solar PV. This underlines the sensitivity in the interaction between the feed-in characteristics of vRES and the EESS with respect to the share of renewables. The deviation in renewable shares could be minimized by implementing an iterative approach that uses information about EESS performance in step 4 as input for step 1, but was beyond the scope in this study.

On the right axis the percentage of the share of flexible bioenergy power plants and EESS is shown in more detail. As in Figure 2, the bars show that EESS contributes significantly to the share of renewables in the solar region, especially for the higher renewables target shares of $65 \%$ and $80 \%$ respctively. This can be explained by the increased amount of excess energy in these scenarios which can be time-shifted to cover power demand at a later time. In contrast, the effect of electrical energy storage on the share of renewables in the wind-dominated region is far less distinct. Here, the contribution of flexible bioenergy is more relevant for reaching the high renewables shares targeted.

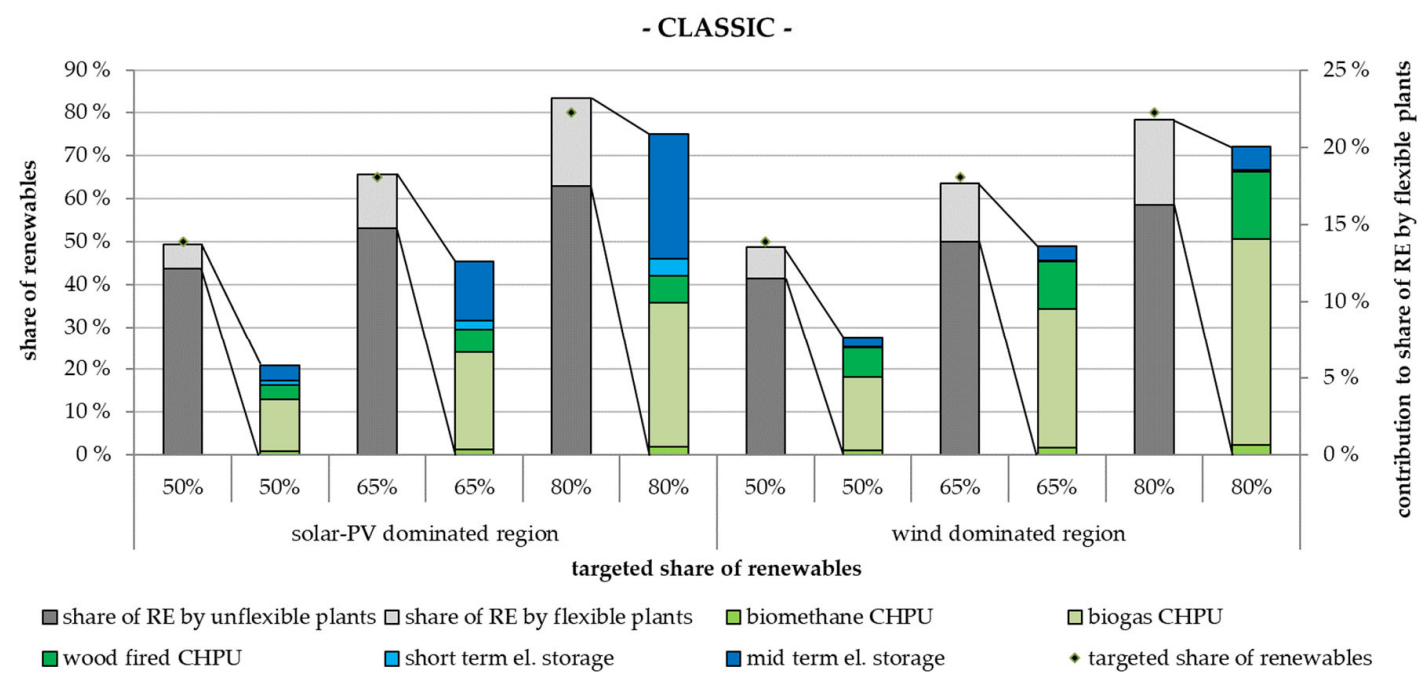

Figure 3. Achieved share of renewables in the electricity consumption of the model regions.

\subsubsection{Characteristic Figures Regarding Operation of the Different Plants and EESS}

The analysis of obtained full load hours and full cycles point out that EESS could be oversized in all scenarios. In the solar-dominated region, short term storages achieve 139-193 full cycles and medium-term storages achieve 16-36 full cycles. Due to the daily excess characteristic of the solar-dominated region a maximum of 365 full cycles could be achieved theoretically for both storage types. Well sized PV-batteries at single family houses typically achieve 250 full cycles [35]. The comparison of achieved full cycles to theoretically achievable full cycles shows that capacity of short term storages is comparatively well used, whereas capacity of medium term storages is clearly oversized.

Flexible biomass plants show on average three starting sequences per day, which matches the maximum allowed number of starting sequences. In contrast, combined-cycle plants show, on average, one starting sequence per day, and hard coal-fired even less.

\subsubsection{Excess Energy and Power}

Table 3 displays the excess energy and excess power that remains after covering the residual load. Comparing both regions, the annual excess energy is higher in the wind-dominated region, whereas the maximum excess power is higher in the solar-dominated region. Both can be explained by regional characteristics. The higher annual excess energy in the wind-dominated region results through the block-like occurrence of excess energy in strong wind phases. Short-term as well as mid-term EESS are only able to store and time-shift a small amount of this excess wind energy. As soon 
as the EESS is full, the remaining excess energy cannot be used in the electricity sector but only in cross-sectoral applications.

Table 3. Remaining excess energy and power after covering of residual load in CLASSIC scenarios.

\begin{tabular}{cccc}
\hline \multirow{2}{*}{ Region } & $\begin{array}{c}\text { Renewables } \\
\text { Share }\end{array}$ & $\begin{array}{c}\text { Annual Excess Energy } \\
\mathbf{( T W h / a )}\end{array}$ & $\begin{array}{c}\text { Maximum Excess Power } \\
\text { (GW) }\end{array}$ \\
\hline \multirow{2}{*}{$\begin{array}{c}\text { Solar PV-dominated } \\
\text { region }\end{array}$} & $50 \%$ & 0 & 0.3 \\
\cline { 2 - 4 } & $65 \%$ & 0.3 & 9.5 \\
\hline \multirow{3}{*}{ Wind-dominated region } & $80 \%$ & 4.9 & 18.2 \\
\cline { 2 - 4 } & $50 \%$ & 0.1 & 3.4 \\
\cline { 2 - 4 } & $65 \%$ & 1.5 & 6.6 \\
\hline
\end{tabular}

Meanwhile, the excess energy occurs regularly in the solar PV-dominated region (in the summer period almost daily), but mainly for a duration of few hours around noon. The comparable high excess power is explainable by the high amount of installed solar PV power. Due to the lower full load hours of solar PV plants in contrast to wind energy plants, more installed power is needed to contribute considerably to residual load covering (cf. Figure 5). That leads to a high feed-in power on days with high solar irradiation and in consequence to high excess energy power.

Instead of curtailing the renewables, the remaining excess energy could be utilized cross-sectionally, e.g., in the heating sector, the mobility sector, or the production sector. Further research to that topic should take into account the different temporally characteristics of occurring excess energy that was described above and is as well depicted as carpet plots in Figure 4. Whereas in wind-dominated regions excess energy occurs only at some days of the year but typically full-time and several days in sequence, the excess energy in solar PV-dominated regions occurs for some hours around noon and has a seasonal character with emphasis on the summer period.
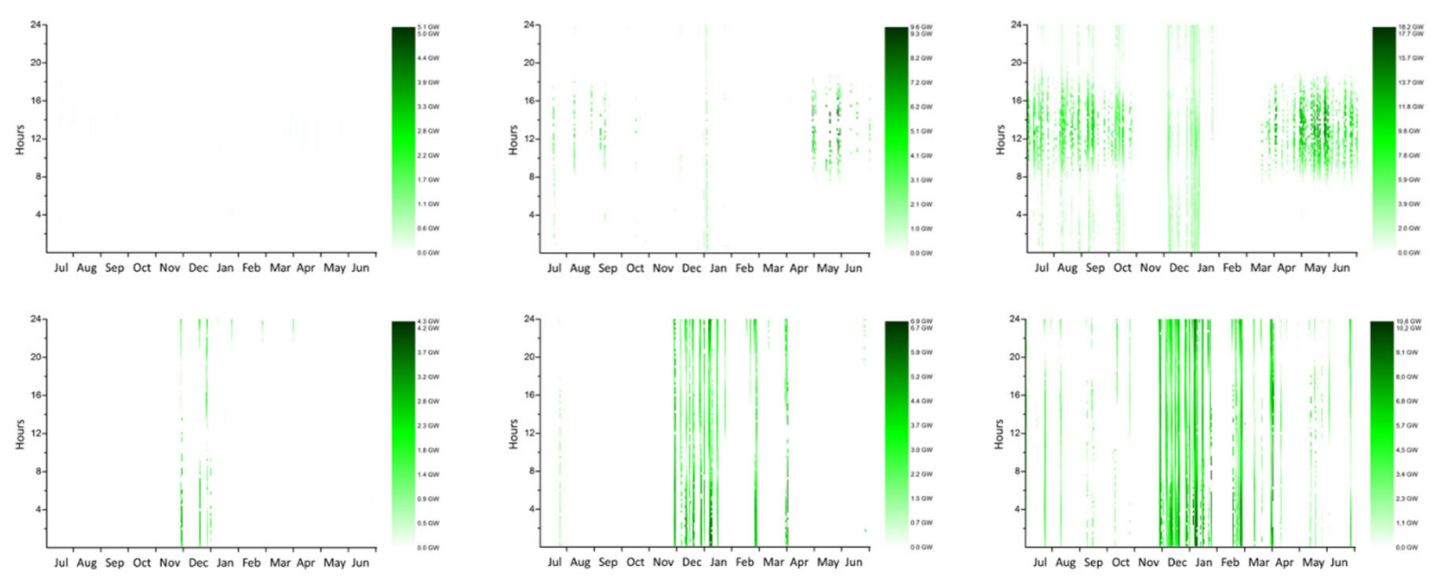

Figure 4. Remaining excess power in each 15-min time step in the different scenarios (above = solar PV-dominated region, below $=$ wind power-dominated region, left $=50 \%$ RES, middle $=65 \%$ RES, right $=80 \%$ RES).

\subsection{Results of the VAREO Scenarios}

This section presents the key results of the VAREO scenarios in order to evaluate the specific contribution of system-friendly wind and solar power for the integration of vRES. Figure 5 provides an overview of the resulting generation capacities in each of the 12 scenarios and allows a side by side comparison of the CLASSIC and VAREO scenarios. 


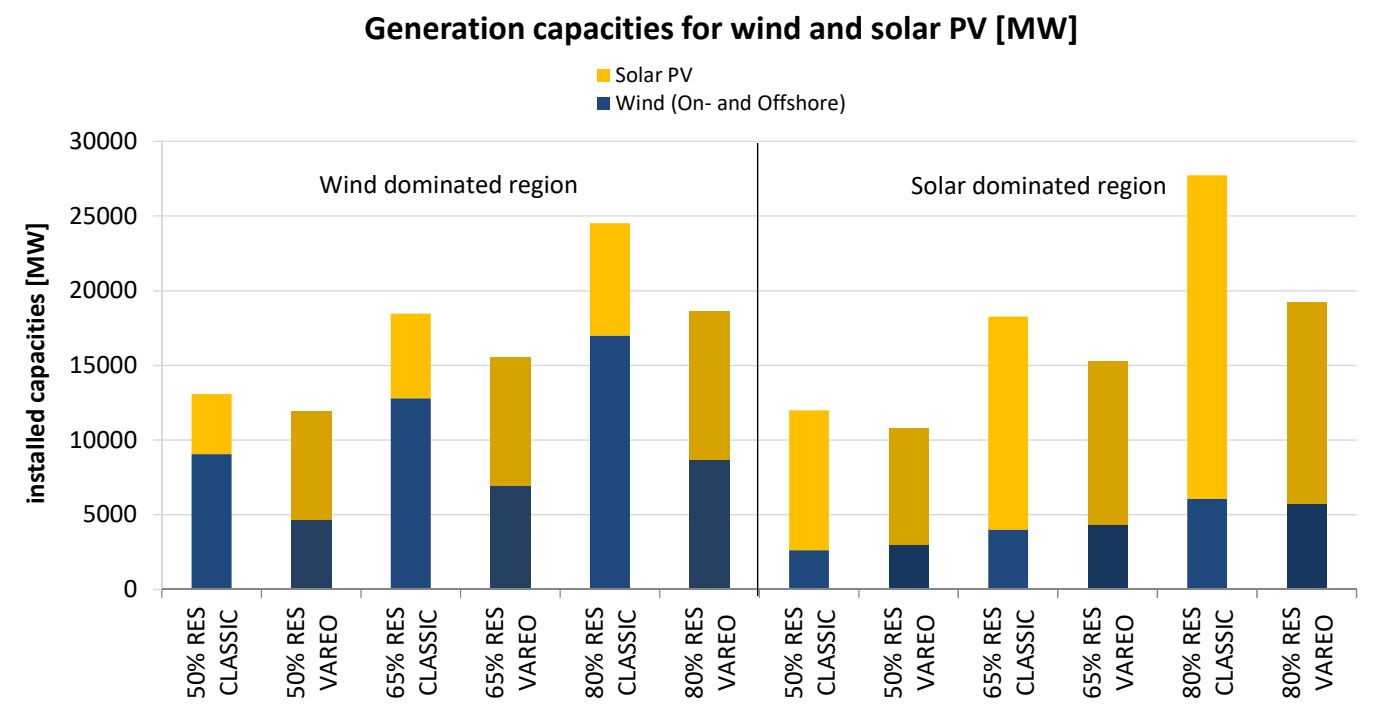

Figure 5. Wind and solar PV generation capacities for the six scenarios in the wind-dominated region (left-hand side) and the six scenarios in the solar PV-dominated region (right-hand side).

In the solar-dominated region, solar PV clearly has the higher installed capacities in comparison to the capacities from wind energy, and also in the endogenously optimized VAREO scenarios. However, the overall capacities from wind and solar, as well as the relative share of solar PV in the capacity mix, decrease in comparison to the CLASSIC scenarios. Whereas in the CLASSIC scenarios for the wind-dominated region, the endogenously optimized VAREO scenarios lead to a higher share of solar PV. The VAREO scenarios require significantly lesser overall installed capacities in comparison to their CLASSIC scenario counterparts while achieving almost identical shares of renewables (Figure 7). This is the effect of introducing system-friendly layouts as well as optimizing the renewable mix from wind and solar. The optimization in the VAREO scenarios also leads to a less pronounced domination of either a wind- or solar PV-dominated mix in comparison to the CLASSIC scenarios, as can be identified in Figure 5. As a result, more solar PV is optimally deployed in the wind-dominated region and more wind is deployed in the solar-dominated region. Especially system-friendly wind turbines provide a much higher productivity so that less installed capacity is required. Both aspects, the optimized mix of wind and solar PV, as well as system-friendly layouts from both vRES sources, help to reduce the requirement of flexibility from bioenergy or EESS in the first place. This characteristic is observable throughout the 12 scenarios and it will be further analyzed in Section 3.3.

Resulting Residual Load

The reduction of the overall installed capacity is just as relevant, as the residual load duration curves (RLDC), which represent the challenge for the integration of increasing vRES into the power system. The resulting RLDC for the different scenarios are illustrated in the following Figure 6, providing a brief impression of the variability of residual load across the different scenarios (RLDC for the wind-dominated region is provided in the Appendix A). 


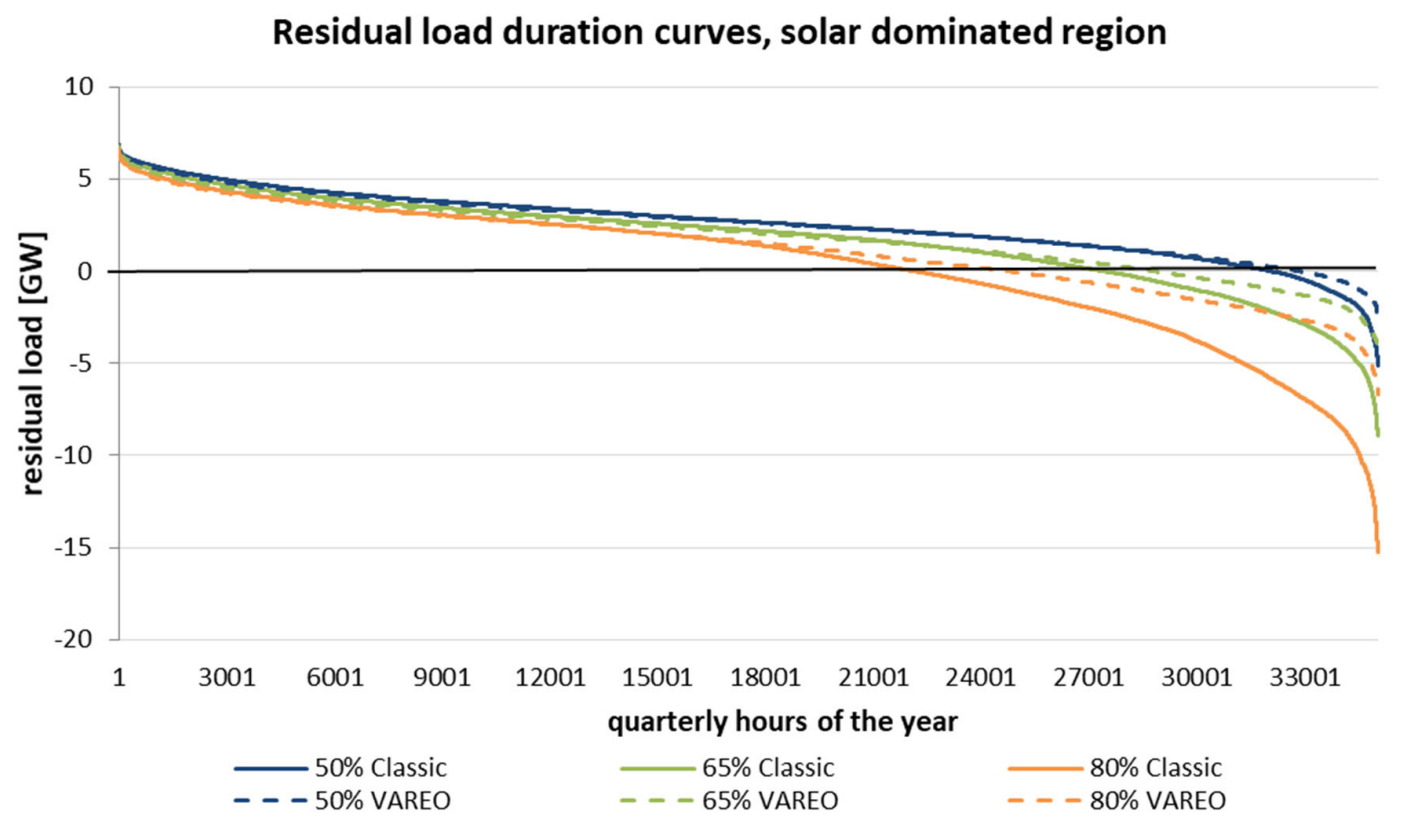

Figure 6. Residual load duration curves of the six different scenarios in the solar-dominated region, showing how the residual loads throughout the sorted annual load values are composed in the three different time periods and either a classical or VAREO optimized mix (dashed lines) of wind and solar PV.

While the left-hand side of the RLDC with positive values for the RL is hardly affected by increasing shares of vRES, the differences on the right-hand side are significant. Here, the amount of excess power (or negative residual load) increases with rising shares of vRES. For all VAREO scenarios (dashed lines), a significant reduction in excess power on the right-hand side of the RLDC can be observed in comparison to the respective CLASSIC scenario. The accumulated annual excess energy resulting from the excess power generation is given in Table 4 together with the relative reduction in excess energy enabled by the VAREO scenarios in comparison to the CLASSIC scenarios. This reduction, which is especially high for the solar-dominated region can to some extent render flexible bioenergy and EESS obsolete (cf. Section 3.3).

Table 4. Comparison between annual negative residual load of CLASSIC and VAREO scenarios.

\begin{tabular}{ccccc}
\hline Region & $\begin{array}{c}\text { Renewables } \\
\text { Share }\end{array}$ & $\begin{array}{c}\text { Annual Negative } \\
\text { Residual Load in } \\
\text { CLASSIC } \\
\text { Scenarios (TWh/a) }\end{array}$ & $\begin{array}{c}\text { Annual Negative } \\
\text { Residual Load in } \\
\text { VAREO Scenarios } \\
\text { (TWh/a) }\end{array}$ & $\begin{array}{c}\text { Percentage of } \\
\text { Reduction in } \\
\text { VAREO Sceanrios } \\
\mathbf{( \% )}\end{array}$ \\
\hline \multirow{2}{*}{$\begin{array}{c}\text { Solar } \\
\text { PV-dominated } \\
\text { region }\end{array}$} & $50 \%$ & 0.9 & 0.3 & -59.9 \\
\cline { 2 - 5 } & $65 \%$ & 4.0 & 1.7 & -56.2 \\
\hline \multirow{2}{*}{$\begin{array}{c}\text { Wind-dominated } \\
\text { region }\end{array}$} & $80 \%$ & 11.8 & 4.4 & -62.9 \\
\cline { 2 - 5 } & $65 \%$ & 0.58 & 0.03 & -94.2 \\
\hline
\end{tabular}

\subsection{Interactions between Different Balancing Options}

In addition to the comparison between CLASSIC and VAREO scenarios, further scenarios were evaluated in a sensitivity analysis (cf. Table 5). This has the goal to reveal competition and synergy between EESS and flexible bioenergy power plants as well as system-friendly solar PV and wind power 
plants. Analogous to CLASSIC and VAREO scenarios, the further scenarios were examined for both regions and the three prospective years, respectively. Except for the varied scenario characteristics that are described in Table 5, all other scenario characteristics in the sensitivity analysis are kept unaltered in the CLASSIC scenarios.

Table 5. Further scenarios for sensitivity analysis.

\begin{tabular}{cc}
\hline Scenario Name & Scenario Description \\
\hline "WithoutStorage" & No EESS in the fleet \\
"WithoutBioenergy" & No flexible bioenergy power plants in the fleet \\
"ConstantBioenergy" & Bioenergy power plants with constant feed-in instead of flexible \\
operation ability & Bioenergy power plants with constant feed-in instead of flexible \\
operation ability and no EESS in the fleet
\end{tabular}

Figure 7 summarizes the achievable share of renewables in all calculated scenarios. The red line depicts each targeted share of renewables. By means of this overview, the interaction of the different balancing options can be deduced. At first, the results for the solar PV-dominated region are described, followed by the results for the wind-dominated region.

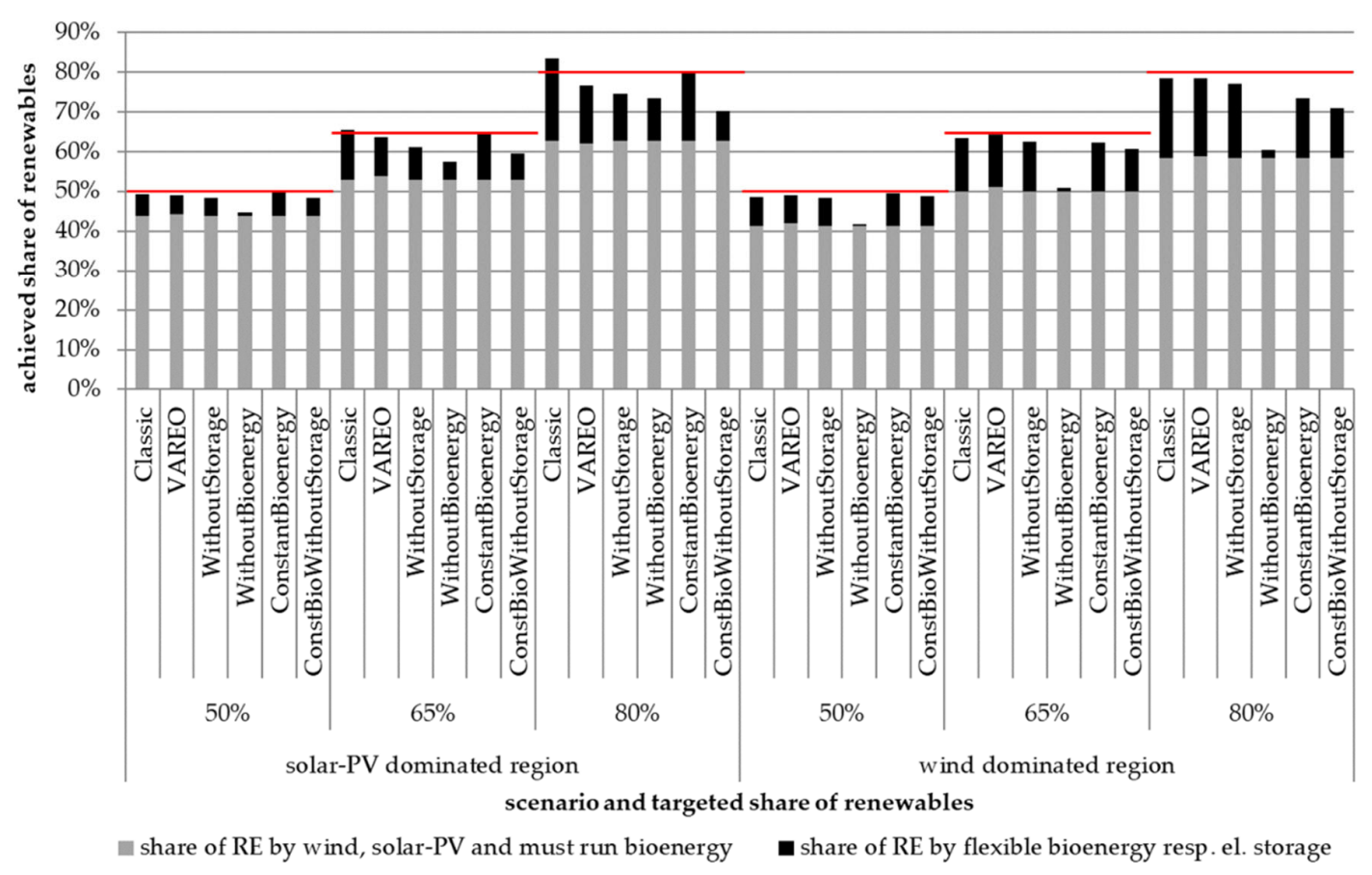

Figure 7. Overview of achieved share of renewables in sensitivity analysis.

\subsubsection{Results Regarding the Solar PV-Dominated Region}

In the solar PV-dominated region VAREO scenarios achieve a slightly lower share of renewables compared to the CLASSIC scenarios. There are two possible explanations. On the one hand, VAREO leads to a smoother residual load curve (cf. Figure 6) which reduces excess energy that could be time-shifted by the modelled EESS. A residual load profile with periodical changes between positive and negative residual load-as it can be observed in the solar PV-dominated region-is most suitable for EESS operation. The reason is that periodical changes between negative and positive residual load lead to alternating charging and discharging, that means a good utilization of the storage capacity. On the other hand, a missing feedback loop between the scenario development in step one (where a certain assumption concerning reusable negative residual load by EESS was met) and the optimization by 
GOMES in step four is responsible for this deviation from the targeted share of renewables, which to a minor extent also occurred in the CLASSIC scenarios.

The removal of EESS in scenario group "WithoutStorage" in comparison to CLASSIC scenarios reduces the achieved share of renewables, too. However, the effect increases with rising targeted share of renewables $(1.0 \%, 4.5 \%$ and $8.8 \%$ respectively). This illustrates that EESS has a growing significance with an increasing share of variable renewables that must be integrated into the energy system.

The removal of flexible bioenergy plants in scenario group "WithoutBioenergy" leads to a significant reduction of achieved shares of renewables $(4.5 \%, 8.1 \%$ and $10.0 \%$ respectively). In contrast to "WithoutStorage", it is striking that the decline in the achieved share of renewables in the $80 \%$ scenario with $10.0 \%$ is not significantly higher as in the $65 \%$ scenario with $8.1 \%$. The reason is that at a high RES share the fleet of EESS can compensate a certain amount of missing bioenergy by time-shifting more energy of negative residual load. Apart from that it becomes apparent that flexible bioenergy plants deliver a direct contribution to reach the renewable targets. In contrast to that EESS has a previous need of negative residual load that can be time-shifted. That means flexible bioenergy plants have the primary purpose of a power producer, which—as a secondary benefit—can partly influence the point in time of production and therefore act in a system-friendly manner. This is also demonstrated by scenario group "ConstantBioenergy", which assumes the same energy production by bioenergy plants as in CLASSIC, but without flexibility. That means the bioenergy plants feed-in power is constant over time. In scenarios with targeted shares of $50 \%$ and $65 \%$ there is no significant difference concerning achieved shares of renewables between CLASSIC and "ConstantBioenergy". Only at a target share of $80 \%$ the inflexibility leads to a reduction of $3 \%$ in the achieved share of renewables.

The compensating effect of the EESS becomes apparent again when comparing the scenario groups "ConstantBioenergy" and "ConstBioWithoutStorage". In "ConstBioWithoutStorage" the achieved shares of renewables decline significantly. In the scenario with a target share of $80 \%$ it is the most unfavorable option, even in comparison to "WithoutBioenergy". It can be deduced that EESS not only time-shifts the negative residual load but also creates additional excess energy generated by constant bioenergy plant operation. Hereby, it compensates the inflexible operation. However, the removal of both balancing options (flexible operation of bioenergy and EESS) weakens the energy system's ability of vRES integration.

\subsubsection{Results for the Wind-Dominated Region}

In the wind-dominated region, the achieved share of renewables is slightly higher in VAREO scenarios in comparison to CLASSIC scenarios. Here, the smoothing effect of system-friendly wind and solar PV plants reduces the block-like occurrence of the negative residual load which was found to be typical for the wind-dominated region. In total, less energy is generated by wind and solar PV plants but it fits better to the power consumption patterns and, therefore, has a higher contribution to the achieved share of renewables. This effect overcompensates the slight reduction of time-shifted energy by the EESS due to the smoothed residual load profile.

The removal of the EESS in the scenario group "WithoutStorage" in contrast to CLASSIC scenarios has a minor effect on the achieved share of renewables $(0.2 \%, 1.0 \%$ and $1.2 \%$ respectively). This was expected as the EESS already showed only a small contribution in CLASSIC scenarios for covering the residual load with respect to the achieved share of renewables.

The removal of bioenergy plants in scenario group "WithoutBioenergy" leads to a significant reduction of the achieved share $(6.8 \%, 12.5 \%$ and $17.9 \%$ respectively) due to the missing energy production as a direct impact—as already explained for the solar PV-dominated region. The higher impact in comparison to the solar PV-dominated region is due the higher amount of available bioenergy, as the share of bioenergy on power consumption ranges from $17 \%$ to $20.3 \%$ in the wind-dominated region against $10.9-13 \%$ in the solar PV-dominated region, depending on the scenario years in both regions. Scenario group "ConstantBioenergy" demonstrates that the flexibility of bioenergy plants plays an important role in the wind-dominated region, at the latest from a targeted share of $65 \%$. One 
additional reason is that-in contrast to the solar PV-dominated region-the EESS can only slightly compensate the missing flexibility of bioenergy plants. Hence, the reduction of the achieved renewables share in scenario group "ConstBioWithoutStorage" is not as distinct as in the solar PV-dominated region.

\subsubsection{Further Results for Both Regions}

By analyzing the further results, it becomes apparent that VAREO scenarios reduce excess energy in both regions and all prospective years. In the solar PV-dominated region excess energy is reduced by $33 \%$, in the wind-dominated region by $93 \%$.

Moreover, the exclusion of flexible bioenergy in scenario group "WithoutBioenergy" is mostly substituted by energy generated by fossil power plants. The scenario with an $80 \%$ target is an exception, due to a sufficient occurrence of negative residual load. In that case, EESS are operated more intensely to time-shift the excess energy. This can compensate the removed amount of flexible bioenergy. This is valid for both regions, even though the effect is much smaller in the wind-dominated region than in the solar PV-dominated region, due to the less regular storage operation.

\section{Conclusions}

\subsection{Balancing Options: EESS and Bioenergy}

Short- and mid-term EESS were found to be suitable balancing options in combination with solar $\mathrm{PV}$, due to the regular diurnal generation pattern. In contrast, flexible bioenergy was more relevant in the wind-dominated region, where excess power production took place in longer periods of strong winds and especially during the winter season. For a wind power-dominated supply, short- and medium-term EESS have limited potential due to their limited storage capacity. Sector coupling may also become a viable option in such cases, especially as the heat demand is also higher in winter [36].

Sensitivity analyses showed only a limited competition between short and medium term EESS versus flexible bioenergy. However, in solar power-dominated regions, EESS can replace flexible bioenergy to some extent.

The capacity of the EESS fleet was dimensioned according to the negative residual load peak, and thus additional storage capacities would show a decreasing marginal utility as only limited additional electric energy can be reintegrated into the electricity system. Therefore, flexible bioenergy complements EESS in the scenarios and serves as a long-term storage, which would be the main competitor.

In contrast to EESS, bioenergy itself is a renewable power source that contributes to a renewable power supply, independent of whether it is produced in a flexible or an inflexible manner. In regional power systems with high shares of vRES and limited flexibility options, a transformation to a flexible and demand driven provision of the limited bioenergy resource is required in order to be able to complement the high volatility of vRES in the power supply.

\subsection{System-friendly Wind and Solar PV}

System-friendly wind and solar power installations depicted within the VAREO-approach led to a less fluctuating power production and less excess power generation. This enables the reduction of required wind and solar generation capacities as well as the need for balancing options, such as EESS. This effect becomes more relevant with increasing shares of renewables. This was especially significant in the wind power-dominated region where $24 \%$ less vRES capacity is required to meet an $80 \%$ renewables share as the overall installed capacity is reduced from $24,513 \mathrm{MW}$ in the CLASSIC scenario to 18,648 MW in the VAREO scenario (compare also Tables A1 and A2 in the Appendix A).

However, in the solar PV-dominated region, a trade-off between reducing surplus power production through system-friendly solar, and the potential for intra-day EESS is particularly significant. The utilization of mid-day power production peaks through EESS is crucial for achieving high shares of renewables, why a focus solely on system-friendly plants without including EESS may not be able to achieve shares of renewables above $80 \%$ in the analyzed island regions. Thus, the utilization of 
surplus power through EESS and the optimized planning of system-friendly solutions requires that both options to be taken into account, ideally in one model (which was not performed here).

Overall, the marginal utility (the proportion of the produced power which can be utilized either directly or through EESS) of the dominating vRES source (wind or solar power, respectively) decreases at higher shares of renewables, while the marginal utility of the respective non-dominant option increases. Therefore, solar power-dominated regions benefit more from increased wind power shares at high shares of renewables, and vice versa. This stresses the importance of an optimized mix from wind and solar PV in accordance with the respective resource potential in the region. A system-friendly mix may increase the resilience of the power system, as it becomes less dependent on flexible options for meeting the power demand, as well as being less affected by (potentially climate change-induced) weather fluctuations.

Compared to the results of other research on balancing options in larger, pan-European power grids $[17,18,37]$, in the here-assessed sub-national region balancing options were found to be necessary at lower shares of renewables in the scenarios. Studies with a similar regional scope for comparison are not known to the authors. A combination of wind and solar power-dominated regions, or a more balanced mix within the regions, would reduce the need for balancing options and, thus, likely reduce costs and environmental effects.

\subsection{Discussion and Future Work}

In this work, the role of balancing options was investigated in clearly defined study regions based on German transmission systems. However, the results can to a large extent be generalized, as the natural supply of variable renewables is similar across most inhabited regions of the world; the diurnal generation pattern of solar PV and seasonal fluctuations of wind power are general characteristics. Thus, the above conclusions apply to many regions in the world. At the same time, regionally-differing conditions, such as availability of bioenergy, hydro power, off-shore wind power, CSP, and power transmission system capacities, as well as differing power demand patterns, are important factors which require a geographically-adapted focus.

In practice, there are interactions with other potential flexibility technologies and some effects can be mitigated by a greater diversity of producers in larger study regions with well-developed power grids. Grid extensions and further balancing options such as demand-side management (DSM), long-term EESS and sector coupling would likely have an impact on the results in the different regions. Such technical solutions have been developed for balancing the power supply, so that aspects such as costs, acceptance, and environmental effects become increasingly relevant. Especially, the cost developments of EESS, as well as for bioenergy, are strongly affected by various independent factors, rendering predictions on the cost-competitiveness of different solutions challenging.

A cost-optimal solution for the power system requires a macroeconomic perspective, where the competitiveness of different solutions is assessed in a system. Notably, system-friendly wind and solar power solutions showcase trade-offs with EESS, which need to be taken into account both from physical as well as from economical perspectives. Not doing so risks leading to sub-optimal solutions, which may hinder and decelerate the development towards high shares of renewables. For further investigations, more complex, integrated simulation and optimization models are necessary, which simultaneously map both the power generation options, including those presented here for more system-friendly PV and wind turbines, as well as all conceivable flexibility technologies. The results of the present study can provide a valuable indication of what should be taken into account in the modelling, design, and evaluation of the scenario calculations.

Author Contributions: The following contributions to the article were made by the authors. Conceptualization: all authors; Methodology: all authors; software: A.K., P.T., B.M., M.D.; data curation, P.T., A.K., B.M., M.D.; writing-original draft preparation: all authors, main contributions from A.K. and P.T.; writing: all authors; visualization: all authors; supervision: M.M.; project administration: M.M. All authors have read and agreed to the published version of the manuscript. 
Funding: This research was funded by Bundesministerium für Wirtschaft und Energie (0325705A-C).

Acknowledgments: This paper is based on the results published in a German project report [38]. We would like to thank Daniela Thrän for support around the research project, Katja Oehmichen and Eva Nebel for their contribution to the life cycle analysis that was also a part of this project, Christian Doetsch and Robert Daschner for their contributions in the initial phase of the project work and Armin von Gleich for his useful comments on the paper draft.

Conflicts of Interest: The authors declare no conflict of interest.

\section{Appendix A}

The installed generation capacities in each of the 12 scenarios are given in the following Tables A1 and A2.

Table A1. Installed renewable capacities for the investigated wind solar PV-dominated region.

\begin{tabular}{|c|c|c|c|c|c|c|}
\hline Renewables Share & $\begin{array}{c}50 \% \\
\text { Renewables }\end{array}$ & $\begin{array}{c}50 \% \\
\text { Renewables }\end{array}$ & $\begin{array}{c}65 \% \\
\text { Renewables }\end{array}$ & $\begin{array}{c}65 \% \\
\text { Renewables }\end{array}$ & $\begin{array}{c}80 \% \\
\text { Renewables }\end{array}$ & $\begin{array}{c}80 \% \\
\text { Renewables }\end{array}$ \\
\hline Szenario & CLASSIC & VAREO & CLASSIC & VAREO & CLASSIC & VAREO \\
\hline Solar PV (east oriented) & - & 4892 & - & 6611 & - & 8006 \\
\hline Solar PV (west oriented) & - & 2892 & - & 4302 & - & 5503 \\
\hline Wind onshore (1546 FLH) & - & - & - & - & - & - \\
\hline Wind offshore (3800 FLH) & \multicolumn{6}{|c|}{ not available in solar dominated region } \\
\hline bioenergy & \multicolumn{6}{|c|}{ flexible and non-flexible modelled separately } \\
\hline hydro & 707 & 707 & 707 & 707 & 707 & 707 \\
\hline other renewables & 137 & 137 & 137 & 137 & 137 & 137 \\
\hline
\end{tabular}

Table A2. Installed renewable capacities for the investigated wind-dominated region.

\begin{tabular}{|c|c|c|c|c|c|c|}
\hline Renewables Share & $\begin{array}{c}50 \% \\
\text { Renewables }\end{array}$ & $\begin{array}{c}50 \% \\
\text { Renewables }\end{array}$ & $\begin{array}{c}65 \% \\
\text { Renewables }\end{array}$ & $\begin{array}{c}65 \% \\
\text { Renewables }\end{array}$ & $\begin{array}{c}80 \% \\
\text { Renewables }\end{array}$ & $\begin{array}{c}80 \% \\
\text { Renewables }\end{array}$ \\
\hline Szenario & CLASSIC & VAREO & CLASSIC & VAREO & CLASSIC & VAREO \\
\hline Solar PV (east oriented) & - & 3953 & - & 4549 & - & 5106 \\
\hline Solar PV (west oriented) & - & 3331 & - & 4089 & - & 4842 \\
\hline Wind onshore (1546 FLH) & 7216 & - & 10189 & - & 13531 & - \\
\hline Wind offshore (3800 FLH) & 1847 & 4576 & 2609 & 5943 & 3465 & 7463 \\
\hline bioenergy & \multicolumn{6}{|c|}{ flexible and non-flexible modelled separately } \\
\hline hydro & 114 & 114 & 114 & 114 & 114 & 114 \\
\hline other renewables & 330 & 330 & 330 & 330 & 330 & 330 \\
\hline
\end{tabular}




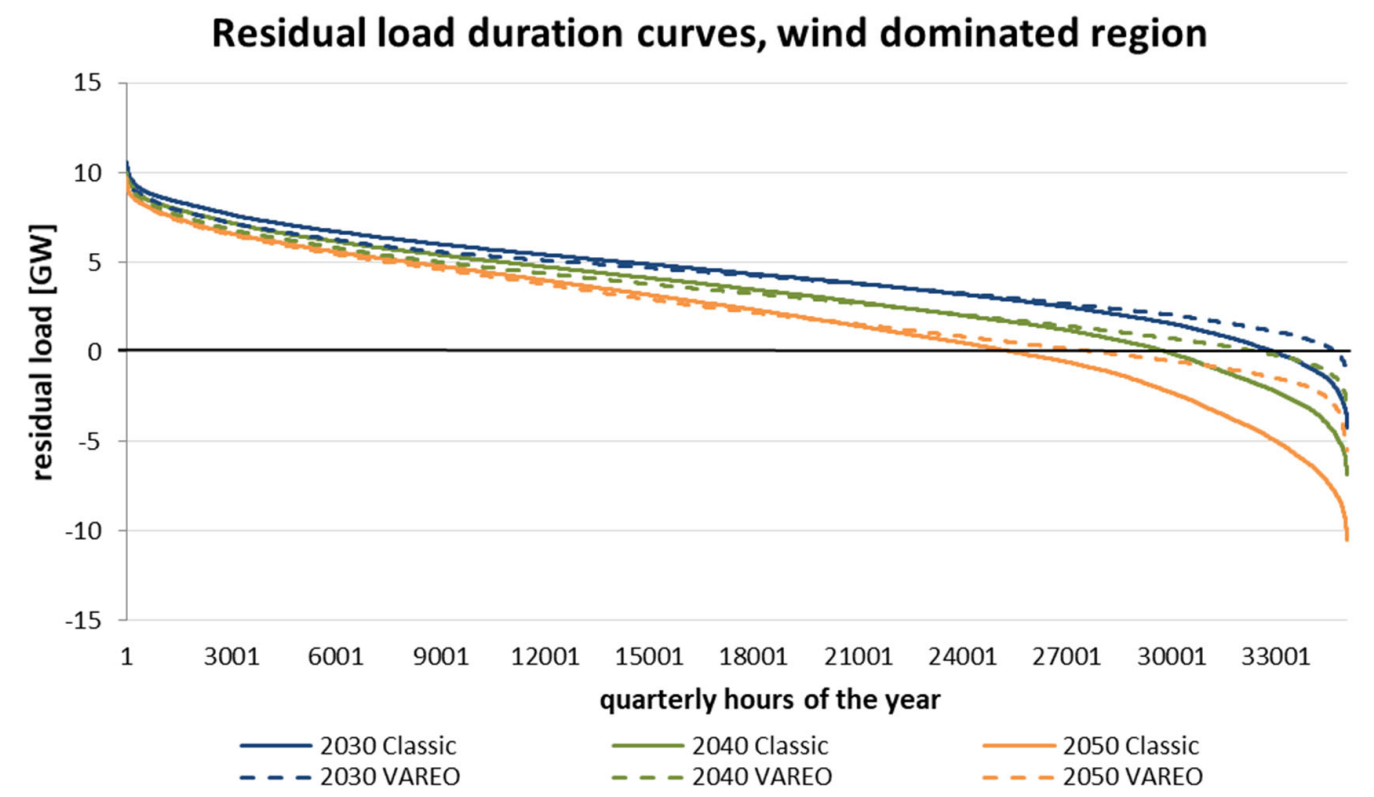

Figure A1. Residual load duration curves of the six different scenarios in the wind-dominated region, showing how the residual loads throughout the sorted annual load values are composed in the three different time periods and either a classical or VAREO optimized mix (dashed lines) of wind and solar PV.

Table A3. Parameter set for biomethane-CHPU reference plant modified and expanded according to [25].

\begin{tabular}{cccccc}
\hline Dimension & Unit & $\mathbf{2 0 1 3}$ & $\mathbf{5 0 \%}$ RES & $\mathbf{6 5 \%}$ RES & $\mathbf{8 0 \%}$ RES \\
\hline $\mathrm{P}_{\text {rated }}$ & $(\mathrm{kW})$ & 167 & 175 & 175 & 175 \\
$\mathrm{P}_{\text {inst }}$ & $(\mathrm{kW})$ & 288 & 300 & 500 & 700 \\
$\mathrm{P}_{\text {min }}$ & $\left(1 \cdot \mathrm{n}^{-1}\right)$ & 0.6 & 0.5 & 0.35 & 0.1 \\
$\mathrm{~m}_{\mathrm{P}+}$ & $\left(1 \cdot \mathrm{n}^{-1} \cdot \mathrm{min}^{-1}\right)$ & 0.20 & 0.20 & 0.40 & 0.60 \\
$\mathrm{~m}_{\mathrm{P}-}$ & $\left(1 \cdot \mathrm{n}^{-1} \cdot \mathrm{min}^{-1}\right)$ & 0.50 & 0.50 & 0.75 & 1.00 \\
$\mathrm{C}_{\mathrm{gs}}$ & $(\mathrm{MWh})$ & n.a. & n.a. & n.a. & n.a. \\
$\mathrm{FLH}$ & $(\mathrm{h})$ & 5080 & 5110 & 3066 & 2190 \\
$\mathrm{Q}_{\mathrm{P}}$ & & 1.72 & 1.71 & 2.86 & 4 \\
$\mathrm{SHR}_{\mathrm{flx}}$ & $(1 / \mathrm{n})$ & 0 & 0.5 & 0.75 & 1 \\
\hline
\end{tabular}

As mentioned above, the technology group "biomethane-CHPU" is depicted as a technology with just one main conversation step because the secondary energy carrier (here methane) is provided by the gas grid. This leads to the fact that this plant type has no storage capacity for intermediates (see Table A8) or, rather, a virtually unlimited storage capacity in terms of the gas grid.

The parameters for the technologies "biogas plant with onsite CHPU" and wood-fired power plant" were given in Tables A4 and A5. The main difference between them is first the absolute degree of flexibility $\left(\mathrm{Q}_{\mathrm{P}}\right)$, where biogas plant can deliver a larger amplitude of controllable load. Furthermore, we assume, that until 2050 the share of biogas plants which will be flexible $\left(\mathrm{SHR}_{\mathrm{flx}}\right)$ rise to $100 \%$, while $20 \%$ of the wood-fired power plants are kept inflexible because of technical restrictions. 
Table A4. Parameter set for biogas plant with on-site CHPU modified and expanded according to $[14,25]$.

\begin{tabular}{cccccc}
\hline Dimension & Unit & $\mathbf{2 0 1 3}$ & $\mathbf{5 0 \%}$ RES & $\mathbf{6 5 \%}$ RES & $\mathbf{8 0 \%}$ RES \\
\hline $\mathrm{P}_{\text {rated }}$ & $(\mathrm{kW})$ & 331 & 330 & 330 & 330 \\
$\mathrm{P}_{\text {inst }}$ & $(\mathrm{kW})$ & 434 & 700 & 1050 & 1400 \\
$\mathrm{P}_{\text {min }}$ & $\left(1 \cdot \mathrm{n}^{-1}\right)$ & 0.6 & 0.5 & 0.4 & 0.3 \\
$\mathrm{~m}_{\mathrm{P}+}$ & $\left(1 \cdot \mathrm{n}^{-1} \cdot \mathrm{min}^{-1}\right)$ & 0.2 & 0.2 & 0.4 & 0.6 \\
$\mathrm{~m}_{\mathrm{P}-}$ & $\left(1 \cdot \mathrm{n}^{-1} \cdot \mathrm{min}^{-1}\right)$ & 0.5 & 0.5 & 0.75 & 1 \\
$\mathrm{C}_{\mathrm{gs}}$ & $(\mathrm{MWh})$ & 1.32 & 2.64 & 3.96 & 5.28 \\
$\mathrm{FLH}$ & $(\mathrm{h})$ & 6681 & 4132 & 2754 & 2066 \\
$\mathrm{Q}_{\mathrm{P}}$ & & 1.31 & 2.12 & 3.18 & 4.24 \\
$\mathrm{SHR}_{\mathrm{flx}}$ & $(1 / \mathrm{n})$ & 0 & 0.5 & 0.75 & 1 \\
\hline
\end{tabular}

Table A5. Parameter set for wood-fired power plant modified and expanded according to [25].

\begin{tabular}{cccccc}
\hline Dimension & Unit & $\mathbf{2 0 1 3}$ & $\mathbf{5 0 \%}$ RES & $\mathbf{6 5 \%}$ RES & $\mathbf{8 0 \%}$ RES \\
\hline $\mathrm{P}_{\text {rated }}$ & $(\mathrm{kW})$ & 2497 & 2500 & 2500 & 2500 \\
$\mathrm{P}_{\text {inst }}$ & $(\mathrm{kW})$ & 4599 & 4750 & 6000 & 7500 \\
$\mathrm{P}_{\mathrm{min}}$ & $\left(1 \cdot \mathrm{n}^{-1}\right)$ & 0.8 & 0.7 & 0.6 & 0.5 \\
$\mathrm{~m}_{\mathrm{P}+}$ & $\left(1 \cdot \mathrm{n}^{-1} \cdot \mathrm{min}^{-1}\right)$ & 0.07 & 0.1 & 0.2 & 0.4 \\
$\mathrm{~m}_{\mathrm{P}-}$ & $\left(1 \cdot \mathrm{n}^{-1} \cdot \mathrm{min}^{-1}\right)$ & 0.07 & 0.1 & 0.2 & 0.4 \\
$\mathrm{C}_{\mathrm{gs}}$ & $(\mathrm{MWh})$ & 0 & 7.5 & 10 & 15 \\
$\mathrm{FLH}$ & $(\mathrm{h})$ & 4756 & 4610 & 3650 & 2920 \\
$\mathrm{Q}_{\mathrm{P}}$ & & 1.84 & 1.9 & 2.4 & 3 \\
$\mathrm{SHR}_{\mathrm{flx}}$ & $(1 / \mathrm{n})$ & 0 & 0.4 & 0.6 & 0.8 \\
\hline
\end{tabular}

Table A6. AHP input data for medium-term EESS system for the years 2030, 2040, and 2050. The data used stems from [39-44].

\begin{tabular}{|c|c|c|c|c|}
\hline \multicolumn{5}{|c|}{ AHP Input Data for Medium-Term Electric Energy Storage System for 2030} \\
\hline technical parameters & High-temperature-storage & Compressed-air-energy & Pump-hydro & redox-flow \\
\hline Efficiency $(\%)$ & 80 & 69 & 80 & 82 \\
\hline Self-discharge & 5 & 5 & 5 & 5 \\
\hline Plant availability & 4 & 4 & 5 & 4 \\
\hline Cyclebility & 3 & 4 & 4 & 3 \\
\hline Lifespan (a) & 15 & 40 & 40 & 20 \\
\hline \multicolumn{5}{|l|}{ Economic parameters } \\
\hline Power-related cost $(€ / k W)$ & 5 & 23 & 15 & 1 \\
\hline $\begin{array}{c}\text { Capacity-related cost } \\
(€ / \mathrm{kWh})\end{array}$ & 1 & 1 & 0 & 0 \\
\hline Value-added competitive & 5 & 5 & 5 & 5 \\
\hline Operating cost $(€ /(\mathrm{kW} \cdot \mathrm{a})$ & 45 & 14 & 12 & 6 \\
\hline Starting cost (€/MW) & 2 & 15 & 2 & 1 \\
\hline \multicolumn{5}{|l|}{ Environmental effects } \\
\hline Land use & 5 & 4 & 1 & 4 \\
\hline Environmental hazards & 2 & 4 & 3 & 3 \\
\hline $\begin{array}{l}\text { Operational emissions } \\
(\mathrm{kg} \mathrm{CO} 2 \mathrm{e} / \mathrm{kW})\end{array}$ & 0.139 & 0.251 & 0.139 & 0.122 \\
\hline $\begin{array}{l}\text { Infrastructure emwissions } \\
\qquad\left(\mathrm{kg} \mathrm{CO}_{2} \mathrm{e} / \mathrm{k}\right)\end{array}$ & 0 & 27 & 60 & 0.02 \\
\hline Raw material criticality & 4 & 4 & 4 & 4 \\
\hline Sustainability & 3 & 3 & 3 & 3 \\
\hline Acceptance & 4 & 4 & 3 & 4 \\
\hline
\end{tabular}


Table A6. Cont.

\begin{tabular}{|c|c|c|c|c|}
\hline \multicolumn{5}{|c|}{ AHP Input Data for Medium-Term Electric Energy Storage System for 2040} \\
\hline Technical parameters & High-temperature-storage & Compressed-air-energy & Pump-hydro & redox-flow \\
\hline Efficiency $(\%)$ & 80 & $\begin{array}{ll}1 & 69\end{array}$ & 80 & 84 \\
\hline Self-discharge & 5 & 5 & 5 & 5 \\
\hline Plant availability & 4 & 4 & 5 & 4 \\
\hline Cyclebility & 3 & 4 & 4 & 3 \\
\hline Lifespan (a) & 15 & 40 & 40 & 20 \\
\hline \multicolumn{5}{|l|}{ Economic parameters } \\
\hline Power-related cost $(€ / \mathrm{kW})$ & 8 & 23 & 15 & 1 \\
\hline $\begin{array}{c}\text { Capacity-related cost } \\
(€ / \mathrm{kWh})\end{array}$ & 1 & 1 & 0 & 0 \\
\hline Value-added competitive & 5 & 5 & 5 & 5 \\
\hline Operating cost $(€ /(\mathrm{kW} \cdot \mathrm{a})$ & 45 & 14 & 12 & 4 \\
\hline Starting cost $(€ / \mathrm{MW})$ & 2 & 15 & 2 & 1 \\
\hline \multicolumn{5}{|l|}{ Environmental effects } \\
\hline Land use & 5 & 4 & 1 & 4 \\
\hline Environmental hazards & 2 & 4 & 3 & 3 \\
\hline $\begin{array}{l}\text { Operational emissions } \\
(\mathrm{kg} \mathrm{CO} 2 \mathrm{e} / \mathrm{kW})\end{array}$ & 0.103 & 0.1852 & 0.103 & 0.079 \\
\hline $\begin{array}{l}\text { Infrastructure emissions } \\
\quad\left(\mathrm{kg} \mathrm{CO}_{2} \mathrm{e} / \mathrm{kW}\right)\end{array}$ & 0 & 27 & 60 & 0.03 \\
\hline Raw material criticality & 4 & 4 & 4 & 4 \\
\hline Sustainability & 3 & 3 & 3 & 3 \\
\hline Acceptance & 4 & 4 & 3 & 4 \\
\hline \multicolumn{5}{|c|}{ AHP Input Data for Medium-Term Electric Energy Storage System for 2050} \\
\hline Technical parameters & High-temperature-storage & Compressed-air-energy & Pump-hydro & redox-flow \\
\hline Efficiency $(\%)$ & 80 & $\begin{array}{ll}1 & 69\end{array}$ & 80 & 85 \\
\hline Self-discharge & 5 & 5 & 5 & 5 \\
\hline Plant availability & 4 & 4 & 5 & 4 \\
\hline Cyclebility & 3 & 4 & 4 & 3 \\
\hline Lifespan (a) & 15 & 40 & 40 & 20 \\
\hline \multicolumn{5}{|l|}{ Economic parameters } \\
\hline Power-related cost $(€ / \mathrm{kW})$ & 8 & 23 & 15 & 1 \\
\hline $\begin{array}{c}\text { Capacity-related cost } \\
(€ / \mathrm{kWh})\end{array}$ & 1 & 1 & 0 & 0 \\
\hline Value-added competitive & 5 & 5 & 5 & 5 \\
\hline Operating cost $(€ /(\mathrm{kW} \cdot \mathrm{a})$ & 45 & 14 & 12 & 4 \\
\hline Starting cost $(€ / M W)$ & 2 & 15 & 2 & 1 \\
\hline \multicolumn{5}{|l|}{ Environmental effects } \\
\hline Land use & 5 & 4 & 1 & 4 \\
\hline Environmental hazards & 2 & 4 & 3 & 3 \\
\hline $\begin{array}{l}\text { Operational emissions } \\
\left(\mathrm{kg} \mathrm{CO}_{2} \mathrm{e} / \mathrm{kW}\right)\end{array}$ & 0.045 & 0.08 & 0.045 & 0.031 \\
\hline $\begin{array}{l}\text { Infrastructure emissions } \\
\quad\left(\mathrm{kg} \mathrm{CO}_{2} \mathrm{e} / \mathrm{kW}\right)\end{array}$ & 0 & 27 & 60 & 0.03 \\
\hline Raw material criticality & 4 & 4 & 4 & 4 \\
\hline Sustainability & 3 & 3 & 3 & 3 \\
\hline Acceptance & 4 & 4 & 3 & 4 \\
\hline
\end{tabular}


Table A7. AHP input data for short-term EESS system. The data used stems from [39-44].

\begin{tabular}{|c|c|c|c|c|c|c|c|c|c|}
\hline \multirow{2}{*}{ Technical Parameters } & \multicolumn{3}{|c|}{$50 \%$ RES Share } & \multicolumn{3}{|c|}{$65 \%$ RES Share } & \multicolumn{3}{|c|}{$80 \%$ RES share } \\
\hline & Lead-Based & Lithium-Based & Nickel-Based & Lead-Based & Lithium-Based & Nickel-Based & Lead-Based & Lithium-Based & Nickel-Based \\
\hline Efficiency (\%) & 75 & 90 & 70 & 75 & 90 & 70 & 80 & 95 & 76 \\
\hline Self-discharge & 4 & 4 & 1 & 4 & 4 & 1 & 4 & 4 & 1 \\
\hline Plant availability & 4 & 5 & 5 & 4 & 5 & 5 & 4 & 5 & 5 \\
\hline Cyclebility & 2 & 3 & 2 & 2 & 3 & 2 & 2 & 3 & 2 \\
\hline Lifespan (a) & 15 & 20 & 10 & 15 & 20 & 10 & 15 & 20 & 10 \\
\hline \multicolumn{10}{|l|}{ Economic parameters } \\
\hline $\begin{array}{l}\text { Power-related cost } \\
(€ / \mathrm{kW})\end{array}$ & 52 & 118 & 97 & 105.25 & 4.8 & 64 & 122.75 & 5.62 & 228.9 \\
\hline $\begin{array}{c}\text { Capacity-related cost } \\
(€ / \mathrm{kWh})\end{array}$ & 104 & 26 & 123 & 210.5 & 53.33 & 250 & 245.5 & 62.44 & 291.96 \\
\hline $\begin{array}{l}\text { Value-added } \\
\text { competitive }\end{array}$ & 5 & 5 & 5 & 5 & 5 & 5 & 5 & 5 & 5 \\
\hline $\begin{array}{l}\text { Operating cost } \\
(€ /(\mathrm{kW} \cdot \mathrm{a})\end{array}$ & 22 & 19 & 22 & 22 & 19 & 22 & 22 & 19 & 22 \\
\hline Starting cost $(€ / \mathrm{MW})$ & 1 & 1 & 1 & 1 & 1 & 1 & 1 & 1 & 1 \\
\hline \multicolumn{10}{|l|}{ Environmental effects } \\
\hline Land use & 5 & 5 & 5 & 5 & 5 & 5 & 5 & 5 & 5 \\
\hline Environmental hazards & 3 & 3 & 2 & 3 & 3 & 2 & 3 & 3 & 2 \\
\hline $\begin{array}{l}\text { Operational emissions } \\
\qquad\left(\mathrm{kg} \mathrm{CO} \mathrm{CO}_{2} \mathrm{e} / \mathrm{kW}\right)\end{array}$ & 0.1859 & 0.062 & 0.239 & 0.0137 & 0.0458 & 0.1767 & 0.0593 & 0.0198 & 0.0763 \\
\hline $\begin{array}{c}\text { Infrastructure } \\
\text { emissions }(\mathrm{kg} \\
\left.\mathrm{CO}_{2} \mathrm{e} / \mathrm{kW}\right)\end{array}$ & 2 & 5 & 3 & 4.16 & 10.03 & 5,45 & 4.85 & $11 ., 7$ & 6.36 \\
\hline Raw material criticality & 5 & 3 & 3 & 5 & 3 & 3 & 5 & 3 & 3 \\
\hline Sustainability & 5 & 3 & 2 & 5 & 4 & 2 & 5 & 4 & 2 \\
\hline Acceptance & 5 & 4 & 3 & 5 & 4 & 3 & 5 & 4 & 3 \\
\hline
\end{tabular}


Table A8. Qualitative assessment of selected parameters used as input for the AHP and utilized in Tables A4 and A6.

\begin{tabular}{cccccc}
\hline Rank & $\mathbf{1}$ & $\mathbf{2}$ & $\mathbf{3}$ & $\mathbf{4}$ & $\mathbf{5}$ \\
\hline Self-discharge (\%/month) & $>20$ & $10-20$ & $5-10$ & $1-5$ & $<1$ \\
Plant availability & very low & low & medium & high & very high \\
Cyclebility & $<1000$ & $1000-5000$ & $5000-10,000$ & $10,000-30,000$ & $>30,000$ \\
Value-added competitive & very high & high & medium & low & None \\
Land use & very high & high & medium & low & very low \\
Environmental hazards & very high & high & medium & low & very low \\
Raw material criticality & very high & high & medium & low & very low \\
Sustainability & very low & low & medium & high & very high \\
Acceptance & very low & low & medium & high & very high \\
\hline
\end{tabular}

Table A9. Global and local weighing factors for medium-term electrical energy storage systems.

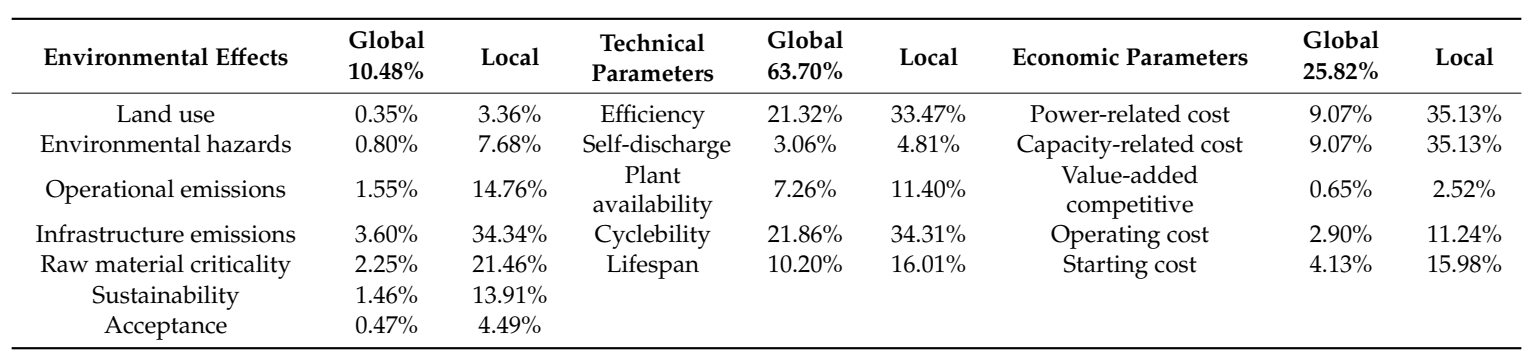

Table A10. Resulting installed electrical storage demand.

\begin{tabular}{|c|c|c|c|c|c|c|}
\hline \multirow[b]{2}{*}{ EESS Type } & \multicolumn{2}{|c|}{$50 \%$ RES Share } & \multicolumn{2}{|c|}{$65 \%$ RES Share } & \multicolumn{2}{|c|}{$80 \%$ RES Share } \\
\hline & $\begin{array}{l}\text { Solar Region } \\
\text { (MW) }\end{array}$ & $\begin{array}{l}\text { Wind Region } \\
\text { (MW) }\end{array}$ & $\begin{array}{l}\text { Solar Region } \\
\text { (MW) }\end{array}$ & $\begin{array}{c}\text { Wind Region } \\
\text { (MW) }\end{array}$ & $\begin{array}{c}\text { Solar Region } \\
\text { (MW) }\end{array}$ & $\begin{array}{c}\text { Wind Region } \\
\text { (MW) }\end{array}$ \\
\hline Lead-based & 434 & 186 & 601 & 205 & 884 & 269 \\
\hline Lithium-based & 504 & 216 & 936 & 320 & 1446 & 440 \\
\hline Nickel-based & 358 & 153 & 520 & 178 & 779 & 237 \\
\hline Compressed-air & 1126 & 1040 & 2112 & 1704 & 3670 & 2452 \\
\hline Pump-hydro & 1517 & 1401 & 2671 & 2155 & 4641 & 3101 \\
\hline Redox-flow & 1898 & 1753 & 3576 & 2884 & 6233 & 4164 \\
\hline
\end{tabular}

Table A11. Overview of the modelled characteristics of fossil fueled power plants, flexible bioenergy plants and EESS.

\begin{tabular}{|c|c|c|c|c|}
\hline Characteristics & $\begin{array}{l}\text { Flexible Bioenergy } \\
\text { Plants }\end{array}$ & $\begin{array}{l}\text { Electric Energy } \\
\text { Storage }\end{array}$ & $\begin{array}{l}\text { Hard Coal and chp } \\
\text { Power Plants }\end{array}$ & $\begin{array}{c}\text { Reserve Power } \\
\text { Plant }\end{array}$ \\
\hline Installed power & $x$ & & $x$ & $x$ \\
\hline Installed storage capacity & $(\mathrm{X})$ & $X$ & & \\
\hline Efficiency factor & $X$ & $x$ & & \\
\hline Part-load range & $x$ & $X$ & $X$ & \\
\hline Ramp rates & $x$ & $x$ & $x$ & \\
\hline $\begin{array}{l}\text { Differentiation between cold } \\
\text { and hot start }\end{array}$ & & & $x$ & \\
\hline $\begin{array}{l}\text { Limitation of daily number } \\
\text { of starts }\end{array}$ & $x$ & & & \\
\hline $\begin{array}{l}\text { Minimum idle time and } \\
\text { minimum operation time }\end{array}$ & & & $x$ & \\
\hline Probability of default & & & $x$ & \\
\hline Reversible self-discharge & $(\mathrm{X})$ & $x$ & & \\
\hline Irreversible self-discharge & & $x$ & & \\
\hline
\end{tabular}




\section{References}

1. BMUB. Klimaschutzplan 2050—Klimaschutzpolitische Grundsätze und Ziele der Bundesregierung. Available online: http://www.bmub.bund.de (accessed on 4 September 2017).

2. Kyritsis, E.; Andersson, J.; Serletis, A. Electricity prices, large-scale renewable integration, and policy implications. Energy Policy 2017, 101, 550-560. [CrossRef]

3. Child, M.; Kemfert, C.; Bogdanov, D.; Breyer, C. Flexible electricity generation, grid exchange and storage for the transition to a 100\% renewable energy system in Europe. Renew. Energy 2019, 139, 80-101. [CrossRef]

4. Schaber, K.; Steinke, F.; Hamacher, T. Transmission grid extensions for the integration of variable renewable energies in Europe: Who benefits where? Energy Policy 2012, 43, 123-135. [CrossRef]

5. Söder, L.; Lund, P.D.; Koduvere, H.; Bolkesjø, T.F.; Rossebø, G.H.; Rosenlund-Soysal, E.; Skytte, K.J.; Blumberga, D. A review of demand side flexibility potential in Northern Europe. Renew. Sustain. Energy Rev. 2018, 91, 654-664. [CrossRef]

6. Tafarte, P.; Das, S.; Eichhorn, M.; Thrän, D. Small adaptations, big impacts: Options for an optimized mix of variable renewable energy sources. Energy 2014, 72, 80-92. [CrossRef]

7. Hirth, L.; Müller, S. System-friendly wind power: How advanced wind turbine design can increase the economic value of electricity generated through wind power. Energy Econ. 2016, 56, 51-63. [CrossRef]

8. Luo, X.; Wang, J.; Dooner, M.; Clarke, J. Overview of current development in electrical energy storage technologies and the application potential in power system operation. Appl. Energy 2015, 137, 511-536. [CrossRef]

9. Beaudin, M.; Zareipour, H.; Schellenberglabe, A.; Rosehart, W. Energy storage for mitigating the variability of renewable electricity sources: An updated review. Energy Sustain. Dev. 2010, 14, 302-314. [CrossRef]

10. Goodenough, J.B. Electrochemical energy storage in a sustainable modern society. Energy Environ. Sci. 2013, 7, 14. [CrossRef]

11. Hadjipaschalis, I.; Poullikkas, A.; Efthimiou, V. Overview of current and future energy storage technologies for electric power applications. Renew. Sustain. Energy Rev. 2009, 13, 1513-1522. [CrossRef]

12. van Hout, M.; Özdemir, Ö.; Koutstaal, P. Large-Scale Balancing with Norwegian Hydro Power in the Future European Electricity Market. ECN-E-17-043; Stichting Energieonderzoek Centrum Nederland (ECN): Petten, The Netherlands, 2017.

13. Thrän, D. Smart Bioenergy: Technologies and Concepts for a More Flexible Bioenergy Provision in Future Energy Systems; Springer: Cham, Switzerland, 2015.

14. Lauer, M.; Thrän, D. Flexible Biogas in Future Energy Systems-Sleeping Beauty for a Cheaper Power Generation. Energies 2018, 11, 761. [CrossRef]

15. Trieb, F.; Fichter, T.; Moser, M. Concentrating solar power in a sustainable future electricity mix. Sustain. Sci. 2014, 9, 47-60. [CrossRef]

16. Schill, W.-P. Residual Load and Storage Requirements for Renewable Integration in Germany; German Institute for Economic Research-DIW: Berlin, Germany, 2013.

17. Heide, D.; Greiner, M.; von Bremen, L.; Hoffmann, C. Reduced Storage and Balancing Needs in a Fully Renewable European Power System with Excess Wind and Solar Power Generation. Renew. Energy 2011, 36, 2515-2523. [CrossRef]

18. Rasmussen, M.G.; Andresen, G.B.; Greiner, M. Storage and balancing synergies in a fully or highly renewable pan-European power system. Energy Policy 2012, 51, 642-651. [CrossRef]

19. NEP. Netzentwicklungsplan Strom 2012: 2.Überarbeiteter Entwurf der Übertragungsnetzbetreiber. 50Hertz, Amprion, TenneTTSO, TransnetBW. 2012. Available online: https://www.netzentwicklungsplan.de/sites/ default/files/nep_2012_2_entwurf_teil_1_kap_1_bis_8.pdf (accessed on 25 February 2020).

20. Nitsch, J.; Pregger, T.; Naegler, T.; Heide, D.; de Tena, D.L.; Trieb, F.; Scholz, Y.; Nienhaus, K.; Gerhard, N.; Sterner, M.; et al. Langfristszenarien und Strategien Für den Ausbau der Erneuerbaren Energien in Deutschland bei Berücksichtigung der Entwicklung in Europa und Global; Deutsches Zentrum für Luft- und Raumfahrt (DLR): Stuttgart/Kassel/Teltow, Germany, 2012.

21. Tafarte, P.; Eichhorn, M.; Thrän, D. Capacity Expansion Pathways for a Wind and Solar Based Power Supply and the Impact of Advanced Technology_A Case Study for Germany. Energies 2019, 12, 324. [CrossRef]

22. IEA International Energy Agency. The Power of Transformation: Wind, Sun and the Economics of Flexible Power Systems; OECD Publishing: Paris, France, 2014. 
23. Hartner, M.; Ortner, A.; Hiesl, A.; Haas, R. East to west-The optimal tilt angle and orientation of photovoltaic panels from an electricity system perspective. Appl. Energy 2015, 160, 94-107. [CrossRef]

24. Johansson, V.; Thorson, L.; Goop, J.; Göransson, L.; Odenberger, M.; Reichenberg, L.; Taljegard, M.; Johnsson, F. Value of wind power-Implications from specific power. Energy 2017, 126, 352-360. [CrossRef]

25. Scheftelowitz, M.; Rensberg, N.; Denysenko, V.; Daniel-Gromke, J.; Stinner, W.; Hillebrand, K.; Naumann, K.; Peetz, D.; Hennig, C.; Thrän, D. Stromerzeugung aus Biomasse: Vorhaben IIa Biomasse. Zwischenbericht Mai 2015. Leipzig. 2015. Available online: https://www.dbfz.de/fileadmin/eeg_monitoring/berichte/01_ Monitoring_ZB_Mai_2015.pdf (accessed on 5 November 2019).

26. Saaty, T.L. Decisions making with the analytic hierachy process. Int. J. Serv. Sci. 2008, 01, 83-98.

27. Nick, M.; Cherkaoui, R.; Paolone, M. Optimal Allocation of Dispersed Energy Storage Systems in Active Distribution Networks for Energy Balance and Grid Support. IEEE Trans. Power Syst. 2014, 29, 2300-2310. [CrossRef]

28. Daim, T.U.; Li, X.; Kim, J.; Simms, S. Evaluation of energy storage technologies for integration with renewable electricity: Quantifying expert opinions. Environ. Innov. Soc. Trans. 2012, 3, 29-49. [CrossRef]

29. Kanngießer, A. Entwicklung Eines Generischen Modells zur Einsatzoptimierung von Energiespeichern für die Techno-Ökonomische Bewertung Stationärer Speicheranwendungen; Karl Maria Laufen: Oberhausen, Germany, 2014.

30. Cludius, J.; Hermann, H.; Matthes, F.C.; Graichen, V. The merit order effect of wind and photovoltaic electricity generation in Germany 2008-2016: Estimation and distributional implications. Energy Econ. 2014, 44, 302-313. [CrossRef]

31. Bloess, A.; Schill, W.-P.; Zerrahn, A. Power-to-heat for renewable energy integration: A review of technologies, modeling approaches, and flexibility potentials. Appl. Energy 2018, 212, 1611-1626. [CrossRef]

32. Buttler, A.; Spliethoff, H. Current status of water electrolysis for energy storage, grid balancing and sector coupling via power-to-gas and power-to-liquids: A review. Renew. Sustain. Energy Rev. 2018, 82, 2440-2454. [CrossRef]

33. Lund, H. Large-scale integration of optimal combinations of PV, wind and wave power into the electricity supply. Renew. Energy 2006, 31, 503-515. [CrossRef]

34. Lund, P.D.; Lindgren, J.; Mikkola, J.; Salpakari, J. Review of energy system flexibility measures to enable high levels of variable renewable electricity. Renew. Sustain. Energy Rev. 2015, 45, 785-807. [CrossRef]

35. Ministerium für Umwelt, Klima und Energiewirtschaft, Baden-Württemberg. Photovoltaik und Batteriespeicher: Technologie, Integration, Wirtschaftlichkeit, 2000th ed.; Stuttgart, Germany, 2017; Available online: https://um.baden-wuerttemberg.de/fileadmin/redaktion/m-um/intern/Dateien/Dokumente/2_Presse_ und_Service/Publikationen/Energie/Photovoltaik-und-Batteriespeicher.pdf (accessed on 25 February 2020).

36. Østergaard, P.A. Comparing electricity, heat and biogas storages' impacts on renewable energy integration. Energy 2012, 37, 255-262. [CrossRef]

37. Schill, W.-P. Residual load, renewable surplus generation and storage requirements in Germany. Energy Policy 2014, 73, 65-79. [CrossRef]

38. Millinger, M.; Tafarte, P.; Dotzauer, M.; Oehmichen, K.; Kanngießer, A.; Meyer, B.; Anna, G.; Anne, H. BalanceE-Synergien, Wechselwirkungen und Konkurrenzen beim Ausgleich fluktuierender erneuerbarer Energien im Stromsektor durch erneuerbare Optionen: Endbericht; Helmholtz Zentrum für Umweltforschung UFZ: Leipzig, Germany, 2017.

39. Sabihuddin, S.; Kiprakis, A.; Mueller, M. A Numerical and Graphical Review of Energy Storage Technologies. Energies 2015, 8, 172-216. [CrossRef]

40. Fraunhofer UMSICHT, Fraunhofer IWES. Metastudie "Energiespeicher". Studie im Auftrag des Bundesministeriums für Wirtschaft und Energie (BMWi). Oberhausen, Kassel, 2014. Available online: https://doi.org/10.24406/UMSICHT-N-484739 (accessed on 25 February 2020).

41. Durand, J.-M.; Duarte, M.J.; Clerens, P. European Energy Storage Technology Development Roadmap towards 2030. 2013. Available online: http://ease-storage.eu/wp-content/uploads/2015/10/EASE-EERArecommendations-Roadmap-LR.pdf (accessed on 25 February 2020).

42. Nair, N.-K.C.; Garimella, N. Battery energy storage systems: Assessment for small-scale renewable energy integration. Energy Build. 2010, 42, 2124-2130. [CrossRef] 
43. Battke, B.; Schmidt, T.S.; Grosspietsch, D.; Hoffmann, V.H. A review and probabilistic model of lifecycle costs of stationary batteries in multiple applications. Renew. Sustain. Energy Rev. 2013, 25, 240-250. [CrossRef]

44. Stürzl, P. A Systematic and Numerical Review of Electrical Energy Storage: A Focus on Performance Parameters. Master's Thesis, Hochschule RheinMain University of Applied Sciences, Wiesbaden Rüsselsheim Geisenheim, Germany, 2015.

(c) (i)

(C) 2020 by the authors. Licensee MDPI, Basel, Switzerland. This article is an open access article distributed under the terms and conditions of the Creative Commons Attribution (CC BY) license (http://creativecommons.org/licenses/by/4.0/). 